\title{
ESTRUTURA E COMPOSIÇÃO DA ICTIOFAUNA DE RIACHOS DA BACIA DO RIO GRANDE NO ESTADO DE SÃO PAULO, SUDESTE DO BRASIL
}

\author{
Autores: Ricardo M. C. Castro ${ }^{1}$; Lilian Casatti ${ }^{2}$; Hertz F. Santos ${ }^{1}$; Alex L. A. Melo ${ }^{\text {; }}$ Luiz S. F. Martins ${ }^{1}$; Katiane M. \\ Ferreira $^{l}$; Fernando Z. Gibran ${ }^{l}$; Ricardo C. Benine ${ }^{l}$; Murilo Carvalho ${ }^{l}$; Alexandre C. Ribeiro ${ }^{l}$; Tatiana X. Abreu ${ }^{1}$; \\ Flávio A. Bockmann ${ }^{\prime}$; Gabriela Z. Pelição ${ }^{1}$; Renata Stopiglia ${ }^{1}$ \& Francisco Langeani ${ }^{2}$
}

Biota Neotropica v4(n1) - http://www.biotaneotropica.org.br/v4n1/pt/abstract?article+BN01704012004

Recebido em: $5 / 12 / 2003$

Publicado em: 30/04/2004

\begin{abstract}
${ }^{1}$ Laboratório de Ictiologia de Ribeirão Preto (LIRP), Departamento de Biologia da FFCLRP-USP (www.ffclrp.usp.br), Av. Bandeirantes 3900, 14040-901 Ribeirão Preto, SP, Brasil (e-mail: rmcastro@ffclrp.usp.br)
\end{abstract}

\begin{abstract}
${ }^{2}$ Departamento de Zoologia e Botânica, IBILCE, Universidade Estadual Paulista (www.ibilce.unesp.br), R. Cristóvão Colombo 2265, 15054-000 São José do Rio Preto, SP, Brasil
\end{abstract}

\begin{abstract}
Eighteen $100 \mathrm{~m}$ long streams stretches, none of an order higher than three, were sampled in three tributaries (six stream stretches sampled in each one) of the left margin of the main channel of Rio Grande (Rios Turvo, Pardo and Sapucaí) in the State of São Paulo, southeastern Brazil. Each stream stretch had its midpoint located with a GPS satellite receiver and had its fish fauna sampled via a standardized environmental data and fish collection methodology (primarily utilizing electrofishing) with the aim of providing the following information about each stream: 1) the taxonomic composition of the fish fauna and the contribution of each species in that stream in terms of both number of individuals and biomass; 2) a photographic documentation of the live coloration of representative specimens of each collected species; and 3) the description of each sampled environment, with colored photographic illustrations and details of the main biotic and abiotic parameters. Overall 3,070 fishes were collected, belonging to six orders, 18 families, 44 genera, and 64 species, with a total biomass of $14.3 \mathrm{~kg}$. Of the collected species, approximately $50 \%$ were Characiformes, $26.5 \%$ Siluriformes, $11 \%$ Perciformes, 6\% Gymnotiformes, 5\% Cyprinodontiformes, and 1.5\% Synbranchiformes. The most abundant species in terms of total number of individuals were Astyanax altiparanae (17.4\%) and Hypostomus ancistroides (9\%); the species with the largest biomasses were Astyanax altiparanae (35\%) and Geophagus brasiliensis (9\%). In terms of abundance and biomass collected for each family, the Characidae was clearly the predominant family followed by the Loricariidae, and Cichlidae. Among the sampled stream stretches, locality SG6 with 26 species and locality PG4 with three species yielded the highest and lowest richness in terms of species numbers, respectively. This coincides with the values obtained for the ShannonWiener index of specific diversity $\left(\mathrm{H}^{\prime}=1.08\right.$ and 0.26 , respectively). The median species richness for all streams stretches was 12. In the species richness estimate by extrapolation for all 18 sampled stream stretches, a value of 93 species was obtained (with a standard error of three) indicating the need for an additional moderate sampling effort to reach the asymptote of the curve. Of the 64 collected species, four (approximately $6 \%$ of the total) are clearly new to science and seven other species (approximately 11\% of the total) are of indefinite taxonomic status and require further analysis. Two of the captured species are certainly introduced (approximately 3\% of the total). Analysis of the trophic and spatial structure of the studied fish fauna indicates that the 10 numerically dominant species in the sampled streams can be grouped, based on published data, into five guilds that are in decreasing order of numeric importance: nektonic omnivores; benthic invertivores; periphytovores; algivores and benthic omnivores. An identification key for all the species of fish collected during this study is provided.
\end{abstract}

Key words: Upper Rio Paraná basin, Rio Grande, Rio Turvo, Rio Pardo, Rio Sapucaí, stream fishes, diversity, southeastern Brazil.

http://www.biotaneotropica.org.br 


\section{Resumo}

Foram amostrados 18 trechos de riachos com $100 \mathrm{~m}$ de extensão, todos de ordem igual ou menor a três, em três tributários (Rios Turvo, Pardo e Sapucaí) da margem esquerda do canal principal do Rio Grande (seis trechos de riacho por tributário), São Paulo. O ponto médio de cada trecho foi georreferenciado via satélite com receptor GPS e o uso de metodologia padronizada de coleta de dados ambientais e peixes (baseada principalmente na pesca elétrica), possibilitou a obtenção das seguintes informações em cada local: 1) composição taxonômica da ictiofauna e contribuição, em termos de número de indivíduos e biomassa, de cada espécie para a ictiofauna local como um todo; 2) documentação fotográfica de espécimes representativos de cada espécie coletada com sua coloração natural; 3) descrição de cada ambiente coletado, com ilustrações fotográficas coloridas, e seus principais parâmetros bióticos e abióticos. No total foram coletados 3.070 exemplares, pertencentes a seis ordens, 18 famílias, 44 gêneros e 64 espécies, com biomassa total de 14,3 kg. Das espécies coletadas, aproximadamente 50\% pertencem a ordem Characiformes, 26,5\% a Siluriformes, $11 \%$ a Perciformes, $6 \%$ a Gymnotiformes, 5\% a Cyprinodontiformes e 1,5\% a Synbranchiformes. As espécies mais abundantes em termos de número de indivíduos foram Astyanax altiparanae (17,4\%) e Hypostomus ancistroides (9\%); aquelas com maior biomassa foram A. altiparanae (35\%) e Geophagus brasiliensis (9\%). Em termos de abundância e biomassa por família, a composição da fauna de peixes estudada indica a predominância expressiva de Characidae, seguida por Loricariidae e Cichlidae. Dentre os trechos amostrados, o trecho SG6 (26 espécies) e o PG4 (três espécies), apresentaram a maior e a menor riqueza em espécies, respectivamente, coincidindo com os valores obtidos para o índice de diversidade específica de Shannon-Wiener $\left(\mathrm{H}^{\prime}=1,08\right.$ e 0,26 , respectivamente). A riqueza média encontrada foi de 12 espécies por trecho de riacho. Na estimativa de riqueza por extrapolação para o conjunto total de riachos amostrados na bacia do Rio Grande, obtivemos um valor de 93 espécies (erro padrão igual a três) indicando ser necessário um esforço amostral adicional moderado para atingir a assíntota da curva. Das 64 espécies coletadas, quatro (aproximadamente $6 \%$ do total) são seguramente novas, sete (aproximadamente $11 \%$ do total) possuem status taxonômico ainda indefinido, enquanto outras duas (aproximadamente 3\% do total) são espécies certamente introduzidas. Analisando a estrutura trófica e espacial da ictiofauna estudada as 10 espécies numericamente dominantes nos riachos amostrados dividem-se, com base em dados de literatura, em ordem decrescente de importância numérica, em cinco guildas: onívoros nectônicos; invertívoros bentônicos; perifitívoros; algívoros e onívoros bentônicos. Uma chave de identificação para todas as espécies de peixes coletadas durante este estudo é fornecida ao final deste trabalho.

Palavras-chave: Bacia do Alto Rio Paraná, Rio Grande, Rio Turvo, Rio Pardo, Rio Sapucaí, peixes de riachos, diversidade, sudeste do Brasil. 


\section{Introdução}

O sistema do Alto Rio Paraná (Figura 1) pertence à região ictiofaunística do Paraná (Géry, 1969) - que inclui os sistemas dos Rios Prata, Uruguai, Paraná e Paraguai, e representa a segunda maior drenagem hidrográfica na América do Sul, com 3,2 milhões de km² (Lowe-McConnell, 1987, 1999). Corresponde à porção da bacia do Rio Paraná situada a montante de Sete Quedas (agora inundada pelo Reservatório de Itaipu), incluindo grandes tributários como os Rios Grande, Paranaíba, Tietê e Paranapanema (ver Castro et al., 2003a, para síntese das informações pertinentes à ictiofauna e estado atual de sua conservação e estudo).

$\mathrm{O}$ presente artigo, referente à porção da bacia de drenagem do Rio Grande contida no Estado de São Paulo [nas sub-bacias/Unidades de Gerenciamento de Recursos Hídricos (UGRH) do Turvo-Grande, Baixo Pardo-Grande e Sapucaí-Grande, Figuras 1 e 2], é o segundo de uma série de três de natureza sintética descritiva, apresentando os dados, agrupados por grandes unidades hidrográficas/geográficas, obtidos durante o desenvolvimento do Projeto Temático do Programa BIOTA/FAPESP - O Instituto Virtual da Biodiversidade (www.biota.org.br), intitulado "Diversidade de peixes de riachos e cabeceiras da bacia do Alto rio Paraná no Estado de São Paulo, Brasil" (www.bdt.fat.org.br/ peixes_pr/) (ver Castro et al., 2003a: 3).

Tal como foi feito em estudo anterior realizado sobre o Rio Paranapanema (Castro et al., 2003a), seus objetivos foram atingidos através da aplicação de uma metodologia padronizada de coleta de dados ambientais e peixes em cada estação de coleta, que possibilitou a obtenção do seguinte conjunto de dados: 1) composição taxonômica da ictiofauna e contribuição, em termos de número de indivíduos e biomassa, de cada espécie para a ictiofauna local como um todo; 2) amplitude de tamanho dos indivíduos amostrados de cada espécie; 3) documentação fotográfica de espécimes representativos de cada espécie coletada com sua coloração natural; 4) descrição dos ambientes amostrados, com ilustrações fotográficas coloridas e seus principais parâmetros bióticos e abióticos. Da mesma forma que no trabalho de Castro et al. (2003a) sobre o Rio Paranapanema, também aqui esperamos que os dados assim obtidos, além de fornecer um retrato instantâneo e testemunho duradouro de cada trecho de riacho no momento de sua amostragem, possam servir também para subsidiar futuros estudos sobre a conservação e manejo de ambientes desse tipo no Estado de São Paulo e no restante do país.

\section{Caracterização da área geral de estudo}

O Rio Grande nasce na Serra da Mantiqueira, nas regiões limítrofes dos Estados de São Paulo e Minas Gerais, a aproximadamente $1.500 \mathrm{~m}$ de altitude $\left(22^{\circ} 15^{\prime} \mathrm{S} 44^{\circ} 34^{\prime} \mathrm{W}\right)$. Apresentando extensão total de $1.050 \mathrm{~km}$ (Ziesler \& Ardizzone, 1979), é uma área de drenagem de aproximadamente 143 mil km² (CEMIG \& CETEC, 2000) que desagua no Rio Paraná, na confluência com o Rio Paranaíba, sendo seus maiores tributários os Rios Sapucaí e Pardo (Ziesler \& Ardizzone, 1979). Em seu curso médio (área amostrada pelo presente estudo), seus afluentes esquerdos drenam terrenos basálticos da Formação Serra Geral, originários do imenso derramamento vulcânico do final do período Jurássico e início do Cretáceo (Rios Sapucaí e Pardo), assim como terrenos areníticos Neocretácicos da Bacia Bauru (a partir do Rio Turvo e em sentido jusante até sua foz no Rio Paraná) (Petri \& Fúlfaro, 1983; Alvarenga et al., 1997; Fernandes \& Coimbra, 2000).

O clima geral nas porções superiores em duas de suas sub-bacias estudadas, do Sapucaí-Grande e do Baixo PardoGrande, é tropical subquente úmido, com três meses secos, passando a tropical quente semi-úmido, com quatro a cinco meses secos nas suas porções médias e inferiores. A terceira sub-bacia estudada, a do Turvo-Grande, encontra-se quase completamente inserida em um clima tropical quente úmido, com três meses secos (Nimer, 1989). A vegetação original da bacia do Rio Grande no Estado de São Paulo era majoritariamente representada pelos Bosques Subtropicais Decíduos e Mesofíticos do Brasil Oriental e Meridional (= Floresta Estacional Semidecidual), com manchas de Campos Cerrados (= Savana) (Huek \& Seibert, 1981; Pesquisa FAPESP, 2003).

A ictiofauna da bacia do Rio Grande, até o momento, foi relativamente pouco estudada. Segundo a última obra geral publicada sobre a ictiofauna do Rio Grande (CEMIG \& CETEC, 2000), na sua bacia são encontradas quatro ordens, seis famílias, 28 gêneros e pelo menos 34 espécies. Infelizmente, assim como os demais grandes rios do Estado de São Paulo, do ponto de vista ambiental, o Rio Grande foi bastante impactado pela construção de um número elevado de barragens hidrelétricas [UHEs Antonio Ermírio de Morais (Água Vermelha), Marimbondo, Porto Colômbia, Volta Grande, Igarapava, Jaguara, Estreito, Peixoto (Mascarenhas de Moraes), Camargos e Itutinga], com uma potência total instalada de 5.616 MW (www.cemig.com.br, www.furnas.com.br, www.polimil.sp.gov.br, 26.xi.2003).

Da vegetação original na área estudada da bacia do Rio Grande contida no Estado de São Paulo, pouco restou. O exame do mapa “O verde em São Paulo" (Pesquisa FAPESP, 2003) permite constatar que na área em questão não há praticamente nenhum fragmento substancial remanescente da vegetação nativa. Tomando como exemplo a bacia do Rio Turvo, parte principal da sub-bacia (=UGRHI) do TurvoGrande, estudada recentemente por Silva \& Martinelli (2001), encontramos somente $15,7 \%$ da vegetação nativa (Floresta Estacional Semidecidual e Savana) remanescente, tendo sido $61,2 \%$ da área alterada pela ação antrópica convertidos a pastagens, $9 \%$ a solo exposto, $7 \%$ a canaviais e $7,1 \%$ convertidos a usos diversos. Todos os 18 trechos de riachos estudados localizavam-se em matas ciliares geralmente 


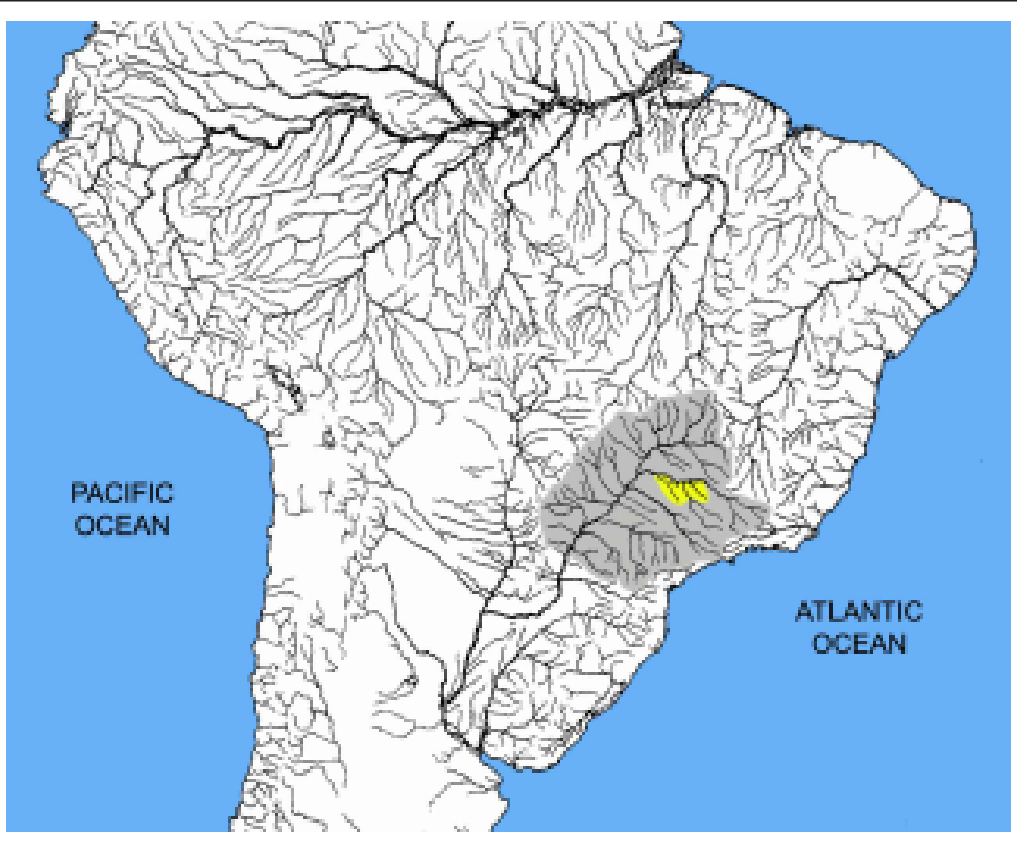

Figura 1. Principais drenagens da América do Sul com a bacia do Alto Rio Paraná (em cinza) e as sub-bacias (= Unidades de Gerenciamento de Recursos Hidricos - UGRHI) do Rio Grande (em amarelo) estudadas.

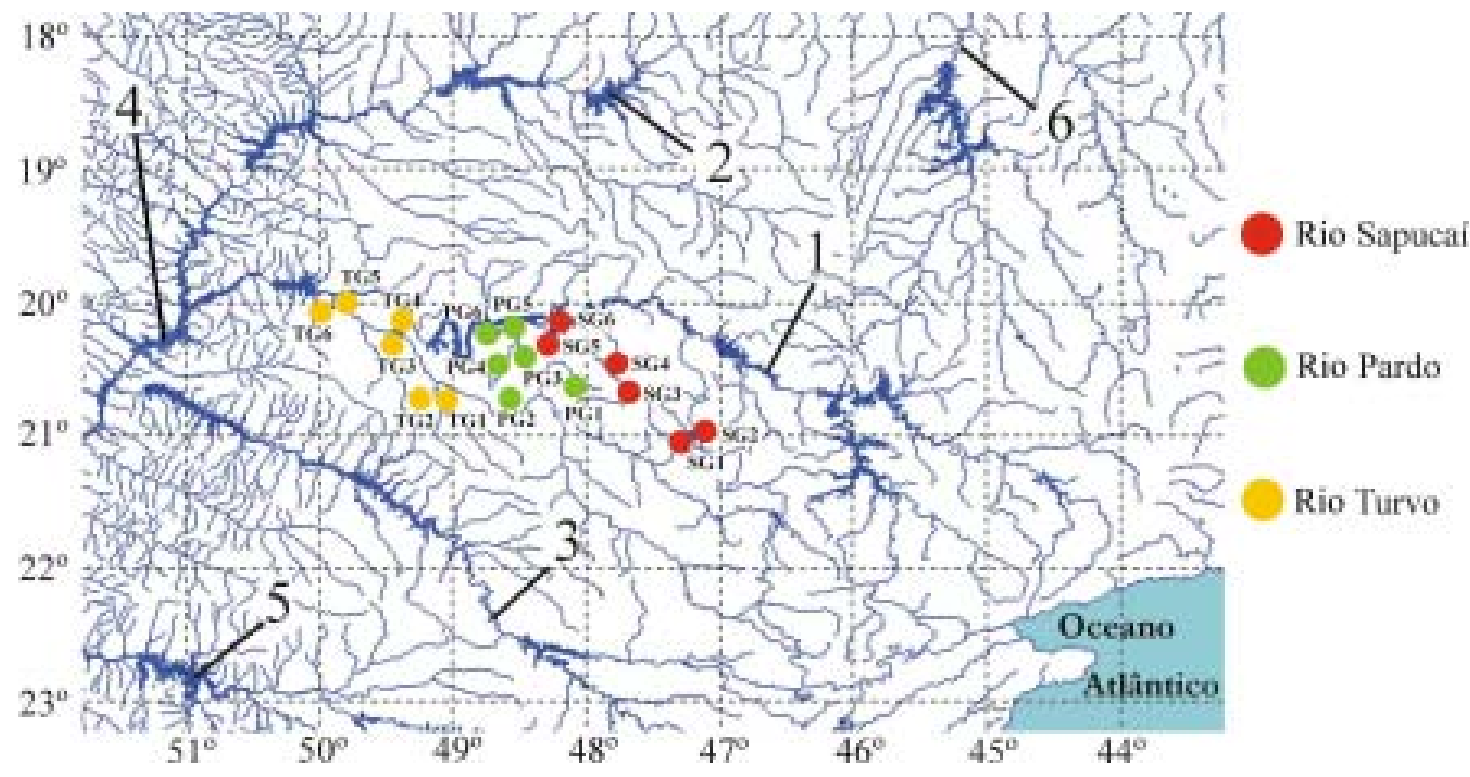

Figura 2. Localização dos 18 trechos de riachos amostrados na bacia do Rio Grande, SP, nas sub-bacias (= Unidades de Gerenciamento de Recursos Hidricos - UGRHI) do Turvo-Grande (TG - amarelo), Baixo Pardo-Grande (PG - verde) e Sapucai-Grande (SG - ocre): 1) Rio Grande, 2) Rio Paranaíba, 3) Rio Tietê, 4) Rio Paraná, 5) Rio Paranapanema, 6) Rio São Francisco. 

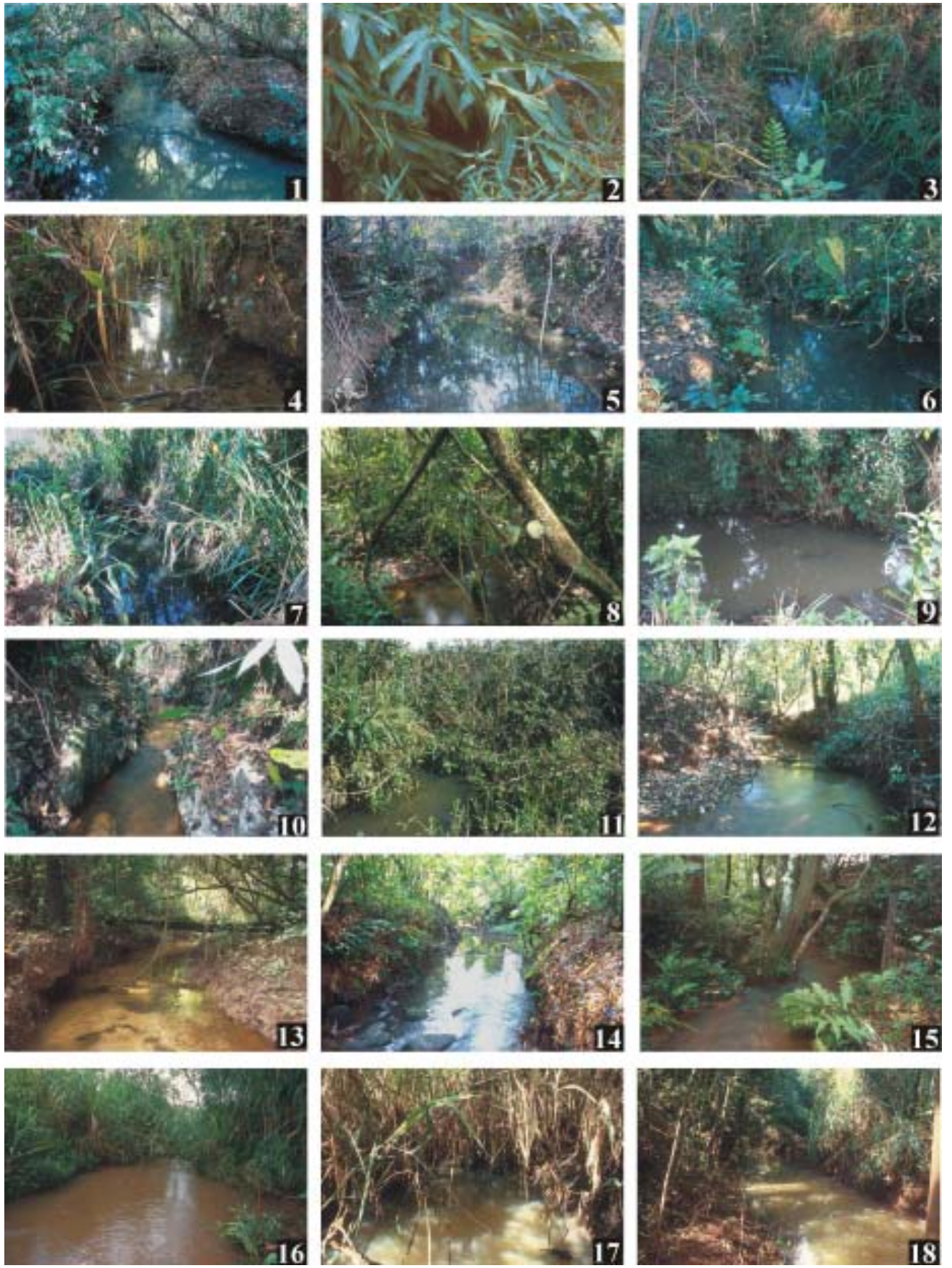

Figura 3. Vistas a partir dos pontos médios dos 18 trechos de riachos amostrados na bacia do Rio Grande, SP, nas sub-bacias (= Unidades de Gerenciamento de Recursos Hídricos - UGRHI) do Turvo-Grande (TG), Baixo Pardo-Grande (PG) e Sapucai-Grande (SG). As respectivas coordenadas geográficas são apresentadas entre parênteses: 1) TG1: Córrego do Macaco (2003'22,1"S 49 $56^{\circ} 46,8^{\prime \prime} W$ ), 2) TG2: Córrego do

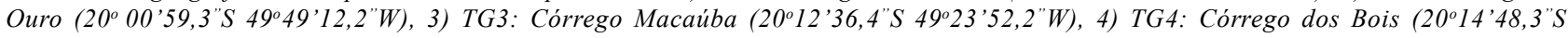

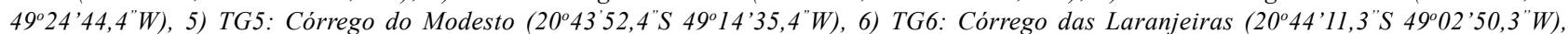
7) PG1: Córrego José Venâncio $\left(20^{\circ} 44^{\prime} 19,4^{\prime \prime} S 48^{\circ} 33^{\prime} 59,5^{\prime \prime} \mathrm{W}\right)$, 8) PG2: Córrego da Batata $\left(20^{\circ} 14^{\prime} 10,2^{\prime \prime S} 48^{\circ} 40^{\prime} 42,0^{\prime \prime} W\right.$ ), 9) PG3: Córrego da

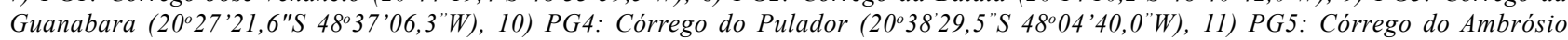

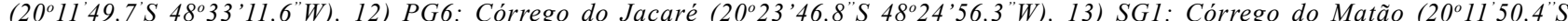

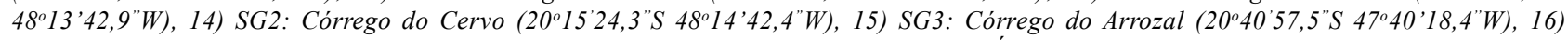

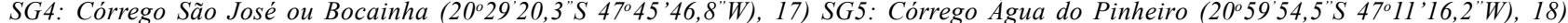
SG6: Riacho sem nome, afluente direto do Rio Pinheiro ou Sapucai $\left(21^{\circ} 00^{\prime} 40,7^{\prime \prime} S 47^{\circ} 13^{\prime} 11,5^{\prime \prime} \mathrm{W}\right.$ ) (Fotos Alexandre C. Ribeiro, Alex L. A. Melo e Ricardo M. C. Castro).

http://www.biotaneotropica.org.br 

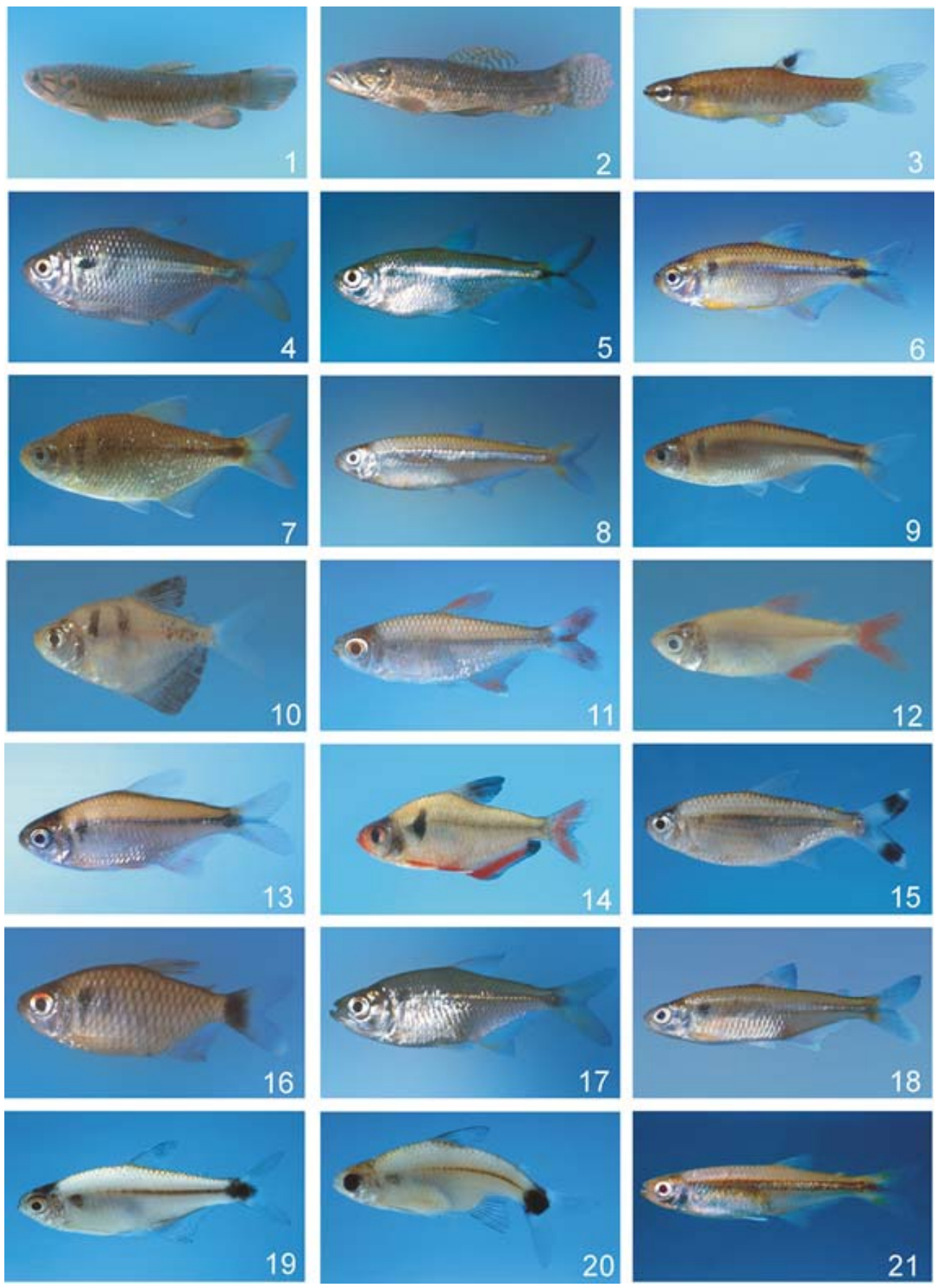

Figura 4a. Exemplares representativos das espécies de peixes da ordem Characiformes coletadas na bacia do Rio Grande, SP, nas sub-bacias (= Unidades de Gerenciamento de Recursos Hidricos - UGRHI) do Turvo-Grande (TG), Baixo Pardo-Grande (PG) e Sapucai-Grande (SG). Os respectivos números de registro na coleção ictiológica do LIRP e comprimentos padrões são apresentados após os nomes das espécies: 1) Hoplerythrinus unitaeniatus, LIRP 2329, 146,0 mm; 2) Hoplias malabaricus, LIRP 2312, 180,3 mm ; 3) Pyrrhulina australis, LIRP 2330, 34,3 $\mathrm{mm}$; 4) Astyanax altiparanae, $L I R P 2877,69,8 \mathrm{~mm}$; 5) Astyanax fasciatus, $L I R P$ 2751, $54,5 \mathrm{~mm}$; 6) Astyanax scabripinnis, $L I R P 2727,26,7$ $m m$; 7) Astyanax sp., LIRP 3538, 70,6 mm; 8) Bryconamericus stramineus, LIRP 2790, 52,3 mm; 9) Bryconamericus $s p .$, LIRP 3503, 48,8 mm; 10) Gymnocorymbus ternetzi, LIRP 3490, 23,6 mm; 11) Hemigrammus marginatus, LIRP 2361, 29,9 mm; 12) Hemigrammus sp., LIRP 3480, 24,9 mm; 13) Hyphessobrycon anisitsi, LIRP 2371, 29,7 mm; 14) Hyphessobrycon eques, LIRP 2378, 30,2 mm; 15) Moenkhausia intermedia, LIRP 2375, 53,3 mm; 16) Moenkhausia sanctaefilomenae, LIRP 2387, 37,4 mm; 17) Oligosarcus pintoi, LIRP 2409, 44,5 mm; 18) Piabina argentea, LIRP 2427, 48,2 mm; 19) Serrapinnus heterodon, LIRP 2488, 27,4 mm; 20) Serrapinnus notomelas, LIRP 2493, 27,4 mm; 21) Planaltina britskii sp., LIRP 2256, 33,3 mm (Fotos Alexandre C. Ribeiro, Alex L. A. Melo e Ricardo M. C. Castro).

http://www.biotaneotropica.org.br 

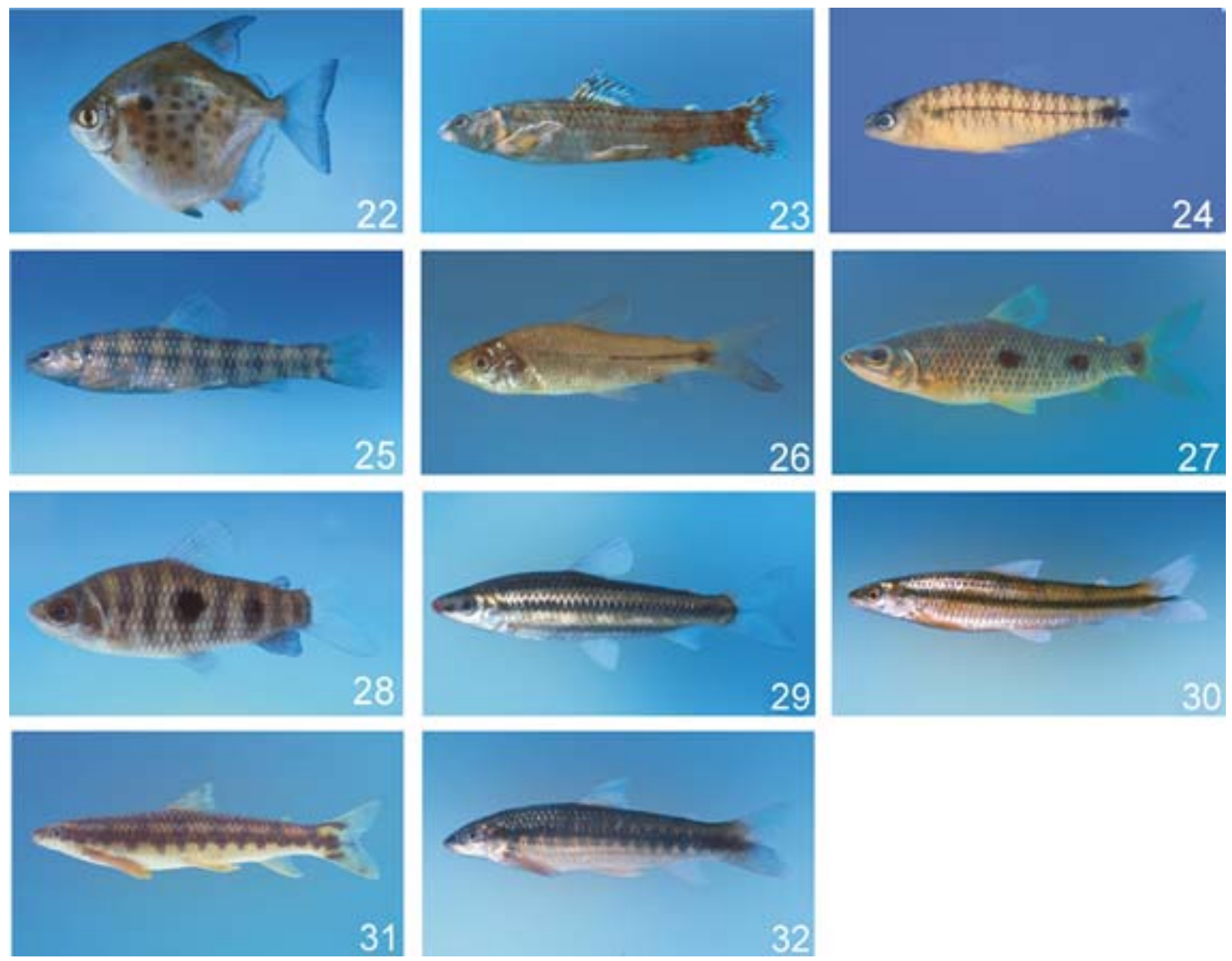

Figura 4b. Exemplares representativos das espécies de peixes da ordem Characiformes coletadas na bacia do Rio Grande, SP, nas sub-bacias (= Unidades de Gerenciamento de Recursos Hídricos - UGRHI) do Turvo-Grande (TG), Baixo Pardo-Grande (PG) e Sapucai-Grande (SG). Os respectivos números de registro na coleção ictiológica do LIRP e comprimentos padrões são apresentados após os nomes das espécies: 22) Metynnis mola, LIRP 2355, 65,3 mm; 23) Characidium gomesi, LIRP 2509, 51,9 mm; 24) Characidium cf. lagosantense, LIRP 2506, 27,9 $\mathrm{mm}$; 25) Characidium zebra, LIRP 2536, 49,9 mm; 26) Steindachnerina insculpta, LIRP 3485, 24,6 mm; 27) Leporinus friderici, LIRP 2335, $143,4 \mathrm{~mm}$; 28) Leporinus lacustris, LIRP 2337, 41,3 mm; 29) Leporinus striatus, LIRP 2250, 55,5 mm; 30) Apareiodon affinis, LIRP 2350, 62,3 mm; 31) Apareiodon ibitiensis, LIRP 3498, 87,3 mm;32) Parodon nasus, LIRP 2366, 71,1 mm (Fotos Alexandre C. Ribeiro, Alex L. A. Melo e Ricardo M. C. Castro). 

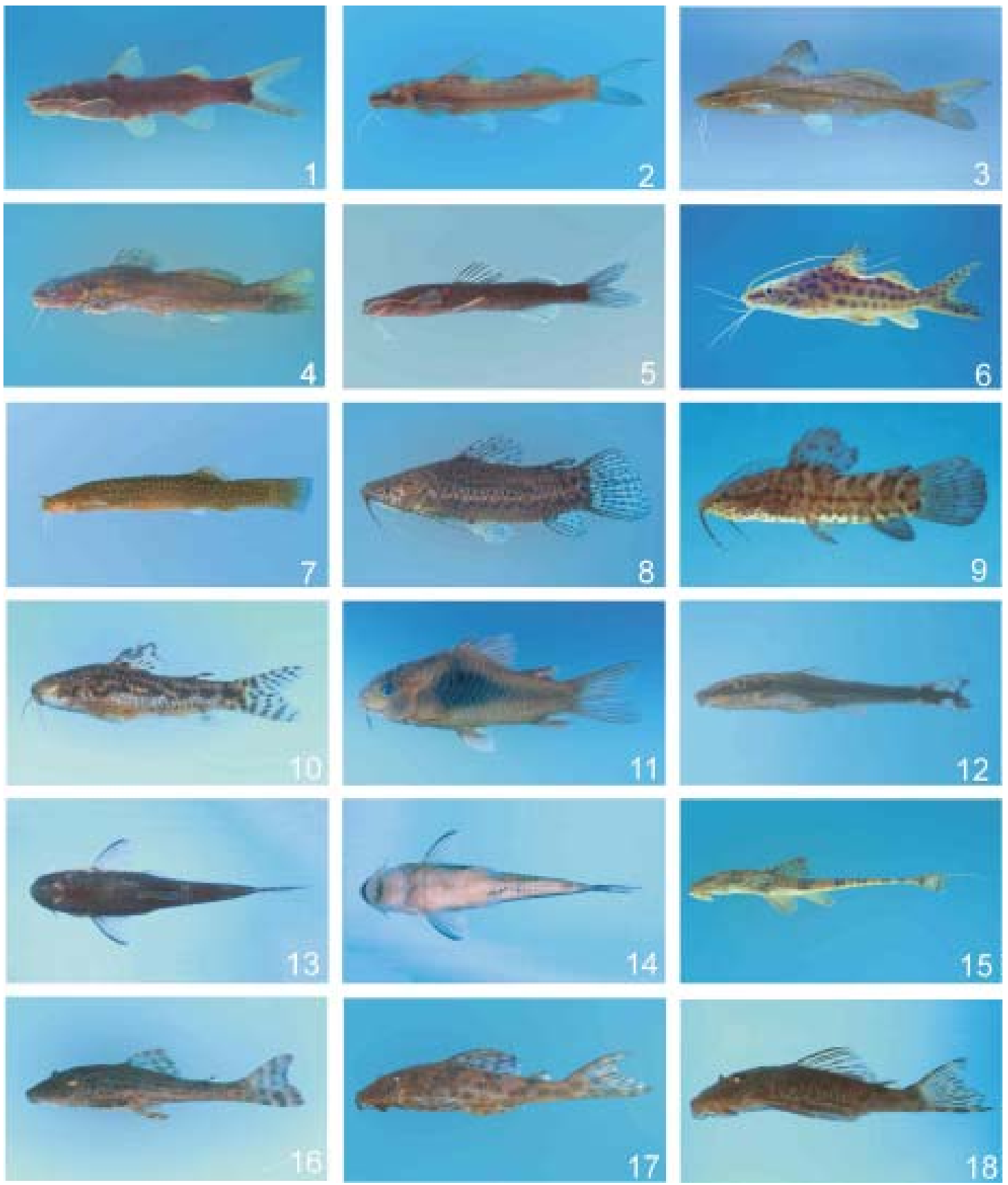

Figura 5. Exemplares representativos das espécies de peixes da ordem Siluriformes coletadas na bacia do Rio Grande, SP, nas sub-bacias (= Unidades de Gerenciamento de Recursos Hídricos - UGRHI) do Turvo-Grande (TG), Baixo Pardo-Grande (PG) e Sapucai-Grande (SG). Os respectivos números de registro na coleção ictiológica do LIRP e comprimentos padrões são apresentados após os nomes das espécies: 1) Cetopsorhamdia iheringi, LIRP 3504, 59,5 mm; 2) Imparfinis schubarti, LIRP 2935, 81,1 mm; 3) Pimelodella sp., LIRP 2926, 89,9 mm; 4) Rhamdia quelen, LIRP 2439, 132,3 mm; 5) Phenacorhamdia tenebrosa, LIRP 2872, 27,2 mm; 6) Pimelodus maculatus, LIRP 2393, $92,3 \mathrm{~mm}$; 7) Trichomycterus brasiliensis, LIRP 3525, $68,3 \mathrm{~mm}$; 8) Lepthoplosternum pectorale, LIRP 2538, $51,7 \mathrm{~mm}$; 9) Megalechis personata, LIRP $3531,33,0 \mathrm{~mm}$; 10) Aspidoras fuscoguttatus, LIRP 2474, 31,6 mm; 11) Corydoras aeneus, LIRP 2546, $37,5 \mathrm{~mm}$; 12) Hisonotus sp., LIRP 3515, 27,6 mm; 13) Hisonotus insperatus, LIRP 2265, $27,9 \mathrm{~mm}$ (vista dorsal); 14) Hisonotus insperatus, LIRP 2265, 27,9 mm (vista ventral); 15) Rineloricaria latirostris, $\operatorname{LIRP} 3533,139,9 \mathrm{~mm}$; 16) Hypostomus ancistroides, LIRP 2689, 35,1 mm; 17) Hypostomus $s p$. ., LIRP 2665 , 98,5 mm; 18) Hypostomus nigromaculatus, LIRP 3226, 49,2 mm (Fotos Alexandre C. Ribeiro, Alex L. A. Melo e Ricardo M. C. Castro). 

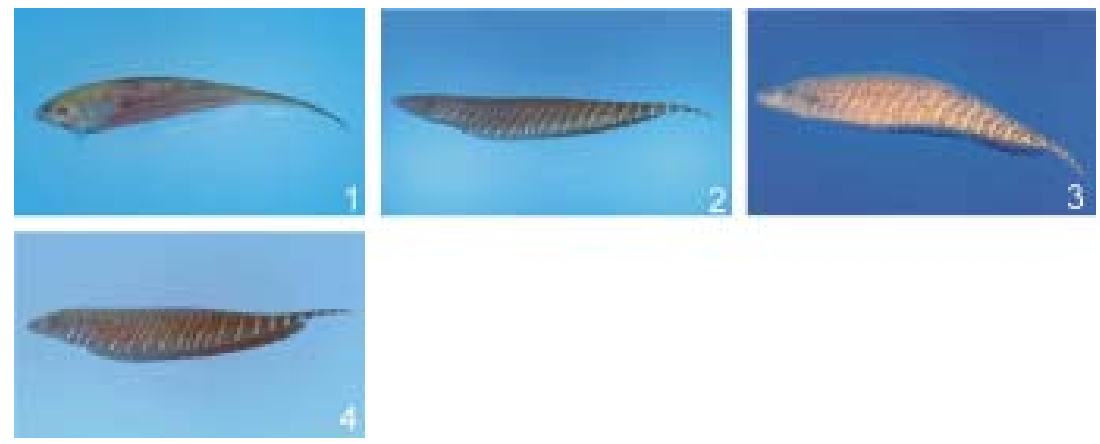

Figura 6. Exemplares representativos das espécies de peixes da ordem Gymnotiformes coletadas coletadas na bacia do Rio Grande, SP, nas sub-bacias (= Unidades de Gerenciamento de Recursos Hídricos - UGRHI) do Turvo-Grande (TG), Baixo Pardo-Grande (PG) e SapucaíGrande (SG). Os respectivos números de registro na coleção ictiológica do LIRP e comprimentos padrões são apresentados após os nomes das espécies: 1) Eigenmannia virescens, LIRP 2823, 174,0 mm; 2) Gymnotus cf. carapo, LIRP 2858, $123,1 \mathrm{~mm}$; 3) Gymnotus cf. inaequilabiatus, LIRP 3472, 282,5 mm; 4) Gymnotus cf. sylvius, LIRP 2851, 119,0 mm (Fotos Alexandre C. Ribeiro, Alex L. A. Melo e Ricardo M. C. Castro).
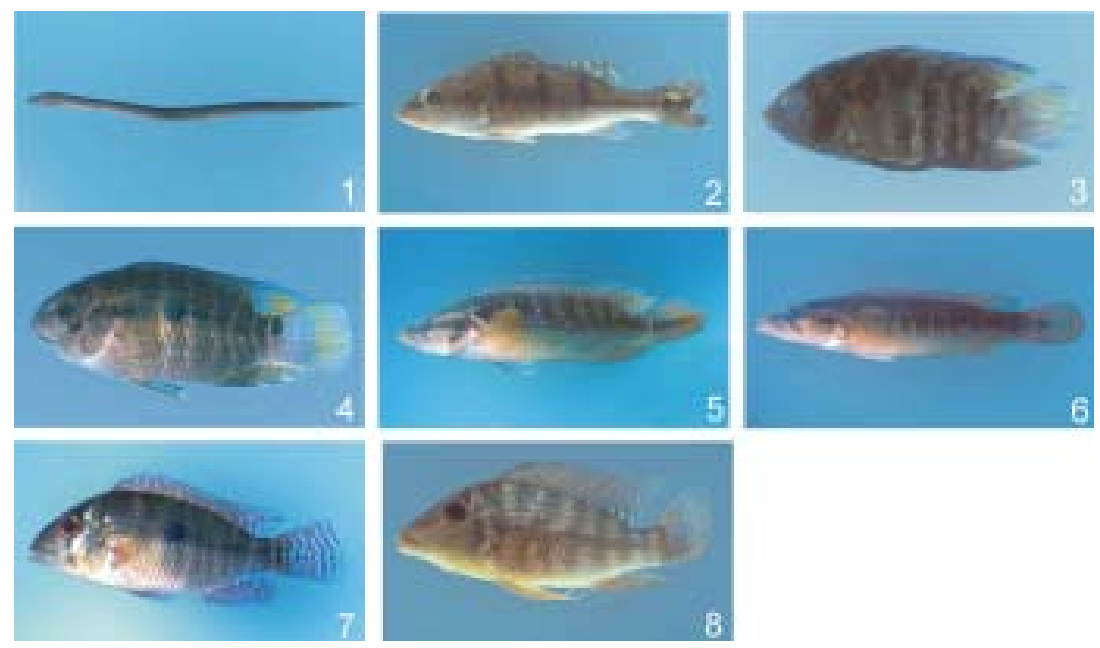

Figura 7. Exemplares representativos das espécies de peixes das ordens Synbranchiformes e Perciformes coletadas na bacia do Rio Grande, SP, nas sub-bacias (= Unidades de Gerenciamento de Recursos Hidricos - UGRHI) do Turvo-Grande (TG), Baixo Pardo-Grande (PG) e Sapucai-Grande (SG). Os respectivos números de registro na coleção ictiológica do LIRP e comprimentos padrões são apresentados após os nomes das espécies: 1) Synbranchus marmoratus, LIRP 2568, 187,3 mm;2) Cichla monoculus, LIRP 3470, 107,0 mm; 3) Cichlasoma facetum, LIRP 2595, 60,3 mm; 4) Cichlasoma paranaense, LIRP 2599, 64,5 mm; 5) Crenicichla britskii, LIRP 2584, 94,2 mm; 6) Crenicichla haroldoi, LIRP 2593, 109,5 mm; 7) Geophagus brasiliensis, LIRP 2649, 67,5 mm; 8) Satanoperca pappaterra, LIRP 3477, 107,5 mm (Fotos Alexandre C. Ribeiro, Alex L. A. Melo e Ricardo M. C. Castro).
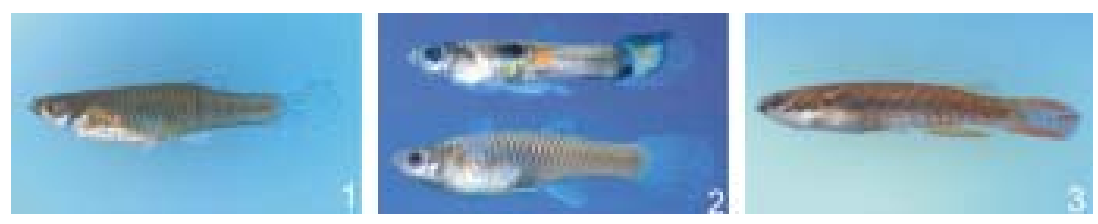

Figura 8. Exemplares representativos das espécies de peixes da ordem Cyprinodontiformes coletadas na bacia do Rio Grande, SP, nas subbacias (= Unidades de Gerenciamento de Recursos Hidricos - UGRHI) do Turvo-Grande (TG), Baixo Pardo-Grande (PG) e Sapucai-Grande (SG). Os respectivos números de registro na coleção ictiológica do LIRP e comprimentos padrões são apresentados após os nomes das espécies: 1) Phalloceros caudimaculatus, LIRP 2615, 30,6 mm ; 2) Poecilia reticulata, LIRP 2634, macho $14,5 \mathrm{~mm}$ (acima), fêmea $21,7 \mathrm{~mm}$ (abaixo); 3) Rivulus pictus, LIRP 2609, 25,5 mm (Fotos Alexandre C. Ribeiro, Alex L. A. Melo e Ricardo M. C. Castro).

http://www.biotaneotropica.org.br 
$\square \%$ Biomassa $\square \%$ Número de Individuos

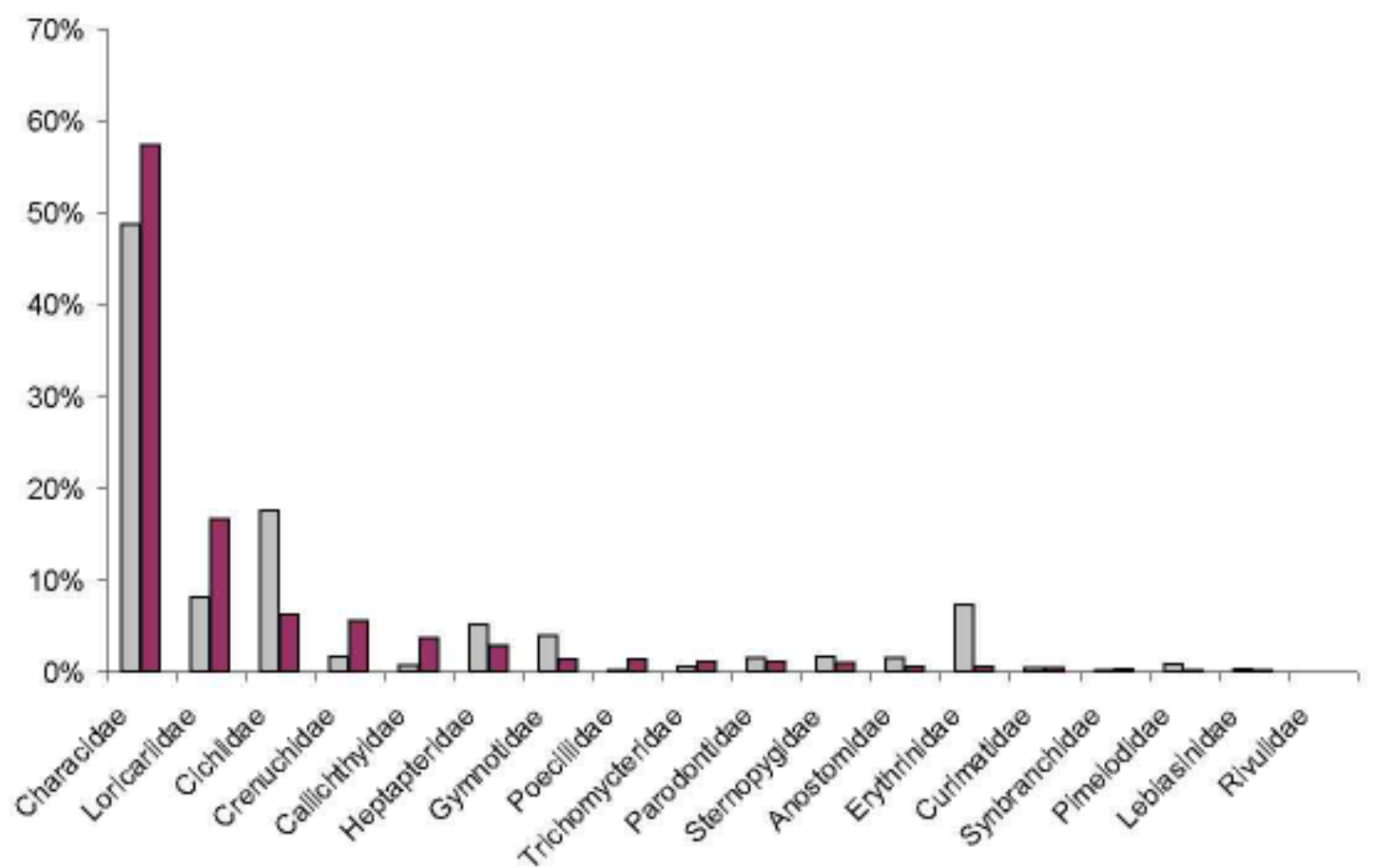

Figura 9. Composição percentual por família, em termos de biomassa e número de indivíduos da totalidade dos peixes coletados nos 18 trechos de riachos amostrados na bacia do Rio Grande, SP, nas sub-bacias (= Unidades de Gerenciamento de Recursos Hidricos - UGRHI) do Turvo-Grande (TG), Baixo Pardo-Grande (PG) e Sapucai-Grande (SG).

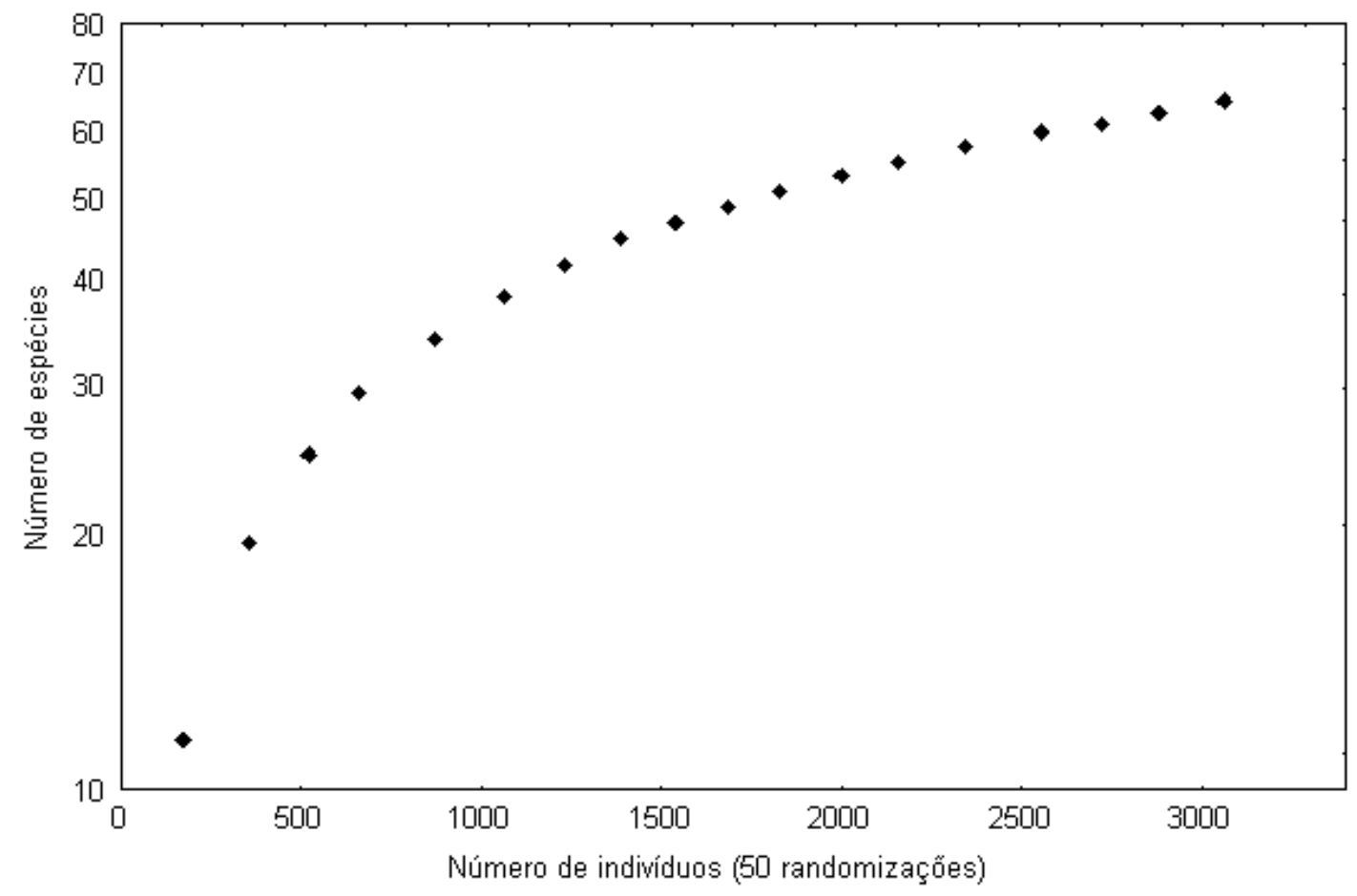

Figura 10. Curva de acumulação do número de espécies observadas em função do número de indivíduos coletados nos 18 riachos da bacia do Rio Grande, SP, nas sub-bacias (= Unidades de Gerenciamento de Recursos Hídricos - UGRHI) do Turvo-Grande (TG), Baixo PardoGrande (PG) e Sapucai-Grande ( $S G)$.

http://www.biotaneotropica.org.br 
estreitas e degradadas em graus variáveis, totalmente cercadas ou por áreas de pastagem ou de cultivo.

\section{Material e métodos}

\subsection{Desenho amostral}

Os 18 trechos de riachos amostrados (Figuras 2 e 3), cada um com aproximadamente $100 \mathrm{~m}$ de extensão, foram escolhidos de tal forma que as localizações destes fossem, na medida do possível, eqüidistantes, ao longo de ambas as margens do canal principal dos rios formadores das subbacias do Turvo-Grande, Baixo Pardo-Grande e SapucaíGrande, sendo três na margem esquerda e três na direita de cada um deles. A definição de riacho adotada é aquela proposta por Castro (1999), e todos os trechos eram de ordem igual ou menor a três (cf. Strahler, 1957). O ponto médio de cada trecho foi georreferenciado via satélite com receptor GPS (Garmin III); as informações sobre os municípios, altitudes e ordens dos trechos de riacho amostrados foram extraídas de cartas 1:50.000 do IBGE e IGGSP.

\subsection{Coleta de dados ambientais}

A informação geral de campo sobre cada trecho de riacho foi padronizada de acordo com o modelo apresentado nas fichas de coleta do Programa BIOTA/FAPESP (ver www.biota.org.br). A documentação fotográfica do ambiente foi feita com uma câmera SLR 35 mm, utilizando-se um tripé posicionado no meio do canal no ponto médio do trecho de riacho.

Os dados de mensuração física do ambiente foram tomados com trena e a velocidade da corrente foi estimada pelo método do objeto flutuante (Brower \& Zar, 1984). A transparência horizontal da água foi estimada com o auxílio de um disco de Secchi. Nas imediações do ponto médio de cada trecho, foi coletada uma amostra de aproximadamente $500 \mathrm{ml}$ do substrato superficial do leito para análise granulométrica. As medidas de temperaturas do ar e da água, $\mathrm{pH}$, oxigênio dissolvido e condutividade foram tomadas com equipamentos digitais portáteis. Amostras das espécies de plantas mais abundantes no local e com algum contato com a água foram coletadas, herborizadas e identificadas até o nível taxonômico possível.

\subsection{Coleta e fotografia de peixes}

Em cada trecho amostrado foi aplicada uma combinação de diversos métodos de captura de forma a ser obtida uma amostra a mais próxima possível da totalidade da ictiofauna nele presente. Assim sendo, o esforço de coleta aplicado a cada método de captura foi tão padronizado quanto possível (ver Castro et al., 2003a para explicação detalhada dos equipamentos e da metodologia de coleta empregados).

Nas extremidades de cada trecho de riacho amostrado foram instaladas redes de bloqueio ( $10 \times 2 \mathrm{~m}, 5 \mathrm{~mm}$ de malha) para impedir a fuga dos peixes. Foram feitas coletas sucessivas (sentido jusante-montante), com duração aproximada de 30 minutos cada, sendo três delas por pesca elétrica (tendo como principal componente um gerador portátil de corrente alternada, produzindo corrente elétrica com $220 \mathrm{~V}, 50-60 \mathrm{~Hz}, 3,4-4,1$ A e $1000 \mathrm{~W})$, duas com uma rede de arrasto manual (3,5 x 1,7 m, $5 \mathrm{~mm}$ de malha) e uma com peneiras metálicas ( $75 \mathrm{~cm}$ de diâmetro, $2 \mathrm{~mm}$ de malha). As passagens com arrastos manuais e peneiras foram intercaladas, sem paradas, entre as passagens de pesca elétrica (ver Castro et al., 2003a).

Todos os exemplares capturados, com exceção daqueles selecionados para fotografia e/ou para extração de amostras de tecido para análises genéticas, foram imediatamente fixados em formalina $10 \%$, por um período mínimo de 48 horas, e transferidos para etanol 70\% para conservação. Todo o material está depositado na coleção do Laboratório de Ictiologia de Ribeirão Preto (LIRP), do Departamento de Biologia da F.F.C.L.R.P. - Universidade de São Paulo (ver item sete). Os indivíduos de cada lote específico foram contados, medidos (comprimento padrão em $\mathrm{mm}$ ) e pesados (g). Para ilustração fotográfica das espécies de peixes coletadas, alguns exemplares foram fotografados vivos, no campo, em vista lateral esquerda, imersos em água, em um pequeno aquário de vidro.

\subsection{Tratamento e análise dos dados}

A diversidade de espécies foi medida através do índice de Shannon-Wiener $\left(\mathrm{H}^{\prime}=-\Sigma\right.$ pi . logpi, onde $\mathrm{p}$ é a freqüência relativa da espécie i) e de Simpson $\left(D=\Sigma \mathrm{pi}^{2}\right)$. A uniformidade da distribuição das espécies foi medida através da eqüitabilidade $\left(\mathrm{e}=\mathrm{H}^{\prime} / \mathrm{Hmax}\right.$, onde Hmax é a diversidade teórica máxima, calculada como o logaritmo em base 10 do número de espécies) (Ludwig \& Reynolds, 1988).

Para avaliar a eficiência do inventário realizado, foi utilizado um estimador de riqueza por extrapolação ("Incidence-based Coverage Estimator", ICE, cf. Lee \& Chao, 1994), que possibilita o cálculo do fator de correção utilizando a incidência (freqüência de ocorrência) de espécies raras. Este procedimento foi realizado com uso do pacote estatístico EstimateS 5, aplicando-se a opção de 50 aleatorizações (Colwell, 1997).

Para a análise da estrutura trófica e espacial predominante nas ictiocenoses, as dez espécies mais abundantes foram ordenadas em ordem decrescente de abundância e classificadas em guildas tróficas, com base na literatura científica pertinente. 


\section{Resultados}

Na Tabela 1 constam os dados de posição geográfica, altitude, hierarquia fluvial (ordem) de todos os trechos de riacho e as datas de coleta. Na Tabela 2 constam a fisiografia, os dados físico-químicos, transparência horizontal da água, granulometria predominante do fundo e tipo da vegetação do entorno. Na Tabela 3 é fornecida uma descrição geral sucinta de cada trecho. Na tabela 4 é sintetizada a estrutura trófica e espacial da ictiofauna estudada para as dez espécies mais abundantes. Na Figura 3, fotografias a partir do ponto médio de cada trecho ilustram os ambientes amostrados.

No total foram coletados 3.070 exemplares, pertencentes a seis ordens, 17 famílias, 44 gêneros e 64 espécies (Tabela 5 e Figuras 4-8), perfazendo uma biomassa total de 14,3 kg. Das espécies coletadas, aproximadamente $50 \%$ pertencem a ordem Characiformes, $26,5 \%$ à Siluriformes, $11 \%$ à Perciformes, $6 \%$ à Gymnotiformes, $5 \%$ à Cyprinodontiformes e 1,5\% à Synbranchiformes. Apenas 32 (aproximadamente $1 \%$ do total) dos exemplares coletados apresentaram comprimento padrão superior a $150 \mathrm{~mm}$ (Tabelas 6a-c). As espécies mais abundantes foram Astyanax altiparanae $(17,4 \%)$ e Hypostomus ancistroides (9\%); as com maior biomassa foram A. altiparanae (35\%) e Geophagus brasiliensis (9\%). A composição da ictiofauna estudada em termos de abundância e biomassa por família indica a predominância expressiva de Characidae seguida por Loricariidae e Cichlidae (Figura 9). Com relação ao número de indivíduos, as ordens Siluriformes e Characiformes tiveram maior representatividade, com aproximadamente $91 \%$ do total coletado. Uma chave de identificação das espécies de peixes coletadas é fornecida no item seis.

A Tabela 4 apresenta as dez espécies mais abundantes na bacia do Rio Grande, e suas respectivas guildas tróficas, distribuições espaciais, assim como as fontes bibliográficas utilizadas para efetuar tal classificação. As espécies em questão (que somadas correspondem a $70 \%$ do total de indivíduos coletados) podem ser divididas em cinco guildas: 1) os onívoros nectônicos, representados por Astyanax altiparanae, Hemigrammus marginatus, Astyanax scabripinnis, Astyanax fasciatus e Piabina argentea (Figuras 4a: 4, 11, 6, 5, 18, respectivamente), correspondendo a 41\% do total de indivíduos; 2 ) os invertívoros bentônicos, incluindo apenas Characidium zebra (Figura 4b: 25), correspondendo a $5 \%$ do total de indivíduos; 3 ) os algívoros, representados por Serrapinnus heterodon (Figura 4a: 19), correspondendo a 6\% do total de indivíduos; 4) os perifitívoros, Hipostomus ancistroides e Hisonotus sp. (Figuras 5: 16, 12, respectivamente), correspondendo a 13,7\% do total de indivíduos; e 5) os onívoros bentônicos, representados unicamente por Geophagus brasiliensis (Figura 7: 7), que corresponde, a 4\% do total de indivíduos coletados.
Dentre os trechos amostrados, o SG6 (com 26 espécies) e o PG4 (com três espécies) apresentaram a maior e a menor riqueza, respectivamente, coincidindo com os maiores e menores valores de Shannon-Wiener $\left(\mathrm{H}^{\prime}=1,08 \mathrm{e}\right.$ 0,26 , respectivamente). A riqueza média por trecho foi de 12 espécies. O trecho TG6 apresentou a maior diversidade de Simpson $(D=0,67)$ enquanto que TG1, TG2 e SG6 apresentaram as menores diversidades deste índice $(\mathrm{D}=$ $0,14)$. A maior eqüitabilidade foi encontrada no trecho SG5 $(e=0,87)$ e a menor foi encontrada no trecho TG6 $(e=0,35)$ (Tabela 7).

A estimativa de riqueza por extrapolação para o conjunto total de riachos amostrados na bacia do Rio Grande indica um valor de 93 espécies (erro padrão igual a três). Analisando a curva de acumulação do número de espécies em função do número de indivíduos coletados (Figura 10), nota-se que, apesar de já estar presente uma tendência à estabilização, ainda seria necessário um esforço amostral adicional para atingir a assíntota da curva.

Das 64 espécies coletadas, uma, Planaltina britskii, foi recentemente descrita (Menezes, et al., 2003) e outras três, Astyanax sp., Bryconamericus sp., Hemigrammus sp., são seguramente novas (as duas primeiras inclusas em manuscritos em preparação). Outras sete das 64 espécies encontradas possuem status taxonômico ainda indefinido: Characidium cf. lagosantense, Pimelodella sp., Gymnotus cf. carapo, Gymnotus cf. inaequilabiatus, Gymnotus cf. sylvius, Hisonotus sp. e Hypostomus sp. (as duas últimas em estudo). Dentre as espécies coletadas, Poecilia reticulata e Cichla monoculus foram certamente introduzidas na região estudada, sendo a primeira originária da América Central e norte da América do Sul (Wischnath, 1993) e a segunda da região Amazônica (Agostinho et al., 1995). A espécie Gymnocorymbus ternetzi, da bacia do Rio Paraguai, Mato Grosso, quase certamente foi também introduzida na bacia do Alto Rio Paraná. Além disso, não é possível precisar se as espécies Hoplerythrinus unitaeniatus, descrita da bacia do Rio São Francisco, Hyphessobrycon eques, descrita da bacia Amazônica, e Satanoperca pappaterra, descrita do Rio Guaporé, na bacia Amazônica, são nativas ou introduzidas na bacia do Alto Rio Paraná.

\section{Discussão}

Tal como foi observado por Castro et al. (2003a) em 17 trechos de riachos estudados no Rio Paranapanema nos Estados de São Paulo e Paraná, as Ordens Siluriformes e Characiformes são taxonomicamente dominantes na bacia do Rio Grande, e somadas representam 76,5\% da diversidade total de espécies dos 18 trechos estudados (ver Castro et al., 2003a para significado de tais dominâncias em comparação com outras áreas da região Neotropical). Os poucos dos indivíduos coletados (apenas 1\%) com mais de $15 \mathrm{~cm}$ de 
Tabela 1. Localização, altitude, hierarquia fluvial (ordem) e data de coleta dos trechos de riachos amostrados nas Unidades de Gerenciamento de Recursos Hidricos (UGRHI) do Turvo-Grande (TG), Baixo Pardo-Grande (PG) e Sapucai-Grande (SG), todas da bacia do Rio Grande, São Paulo.

\begin{tabular}{|c|c|c|c|c|}
\hline Trechos & Localidade & $\begin{array}{c}\text { Altitude } \\
(\mathbf{m})\end{array}$ & Ordem & Data \\
\hline TG1 & $\begin{array}{l}\text { Município de Olímpia, Fazenda Três Corações, Córrego das Laranjeiras } \\
20^{\circ} 44^{\prime} 11,33^{\prime} \mathrm{S} 49^{\circ} 02^{\prime} 50,3 \text { ”W }\end{array}$ & 479 & 3 & 15.vii.2001 \\
\hline TG2 & $\begin{array}{l}\text { Município de Guapiaçu, Estância Santa Rita, Córrego do Modesto } \\
20^{\circ} 43^{\prime} 52,4^{\prime} \text { S } 49^{\circ} 14^{\prime} 35,5^{\prime} \mathrm{W}\end{array}$ & 493 & 3 & 14.vii. 2001 \\
\hline TG3 & $\begin{array}{l}\text { Município de Orindiúva, Córrego dos Bois } \\
20^{\circ} 14^{\prime} 48,3^{\prime} \mathrm{S} 49^{\circ} 24^{\prime} 44,4^{\prime} \mathrm{W}\end{array}$ & 445 & 1 & 13.vii.2001 \\
\hline TG4 & $\begin{array}{l}\text { Município de Orindiúva, Fazenda Bela Vista, Córrego Macaúba } \\
20^{\circ} 12^{\prime} 36,4^{\prime \prime} \mathrm{S} 49^{\circ} 23^{\prime} 52,2^{\prime \prime} \mathrm{W}\end{array}$ & 474 & 2 & 12.vii.2001 \\
\hline TG5 & $\begin{array}{l}\text { Município de Riolândia, Fazenda do Sr. Alfredinho, Córrego do Ouro } \\
\qquad 20^{\circ} 00^{\prime} 59,3 \text { ”S } 49^{\circ} 49^{\prime} 12,2^{\prime \prime} \mathrm{W}\end{array}$ & 407 & 2 & 11.vii.2001 \\
\hline TG6 & $\begin{array}{l}\text { Município de Cardoso, Córrego do Macaco } \\
20^{\circ} 03 \text { '22, 1’S } 49^{\circ} 56^{\prime} 05,2^{\prime} \mathrm{W}\end{array}$ & 396 & 2 & 10.vii.2001 \\
\hline PG1 & $\begin{array}{l}\text { Município de Morro Agudo, Fazenda Santo André, Córrego do Pulador } \\
20^{\circ} 38^{\prime} 29,0^{\prime} \mathrm{S} 48^{\circ} 04^{\prime} 40,7^{\prime} \mathrm{W}\end{array}$ & 577 & 1 & 12.x.2001 \\
\hline PG2 & $\begin{array}{l}\text { Município de Colina, Fazenda Experimental de Zootecnia, Córrego José Venâncio } \\
20^{\circ} 44^{\prime} 14,9^{\prime} \mathrm{S} 48^{\circ} 33^{\prime} 59,5^{\prime \prime} \mathrm{W}\end{array}$ & 576 & 2 & 05.x.2001 \\
\hline PG3 & $\begin{array}{l}\text { Município de Guaíra, Fazenda Bom Sucesso, Córrego do Jacaré } \\
20^{\circ} 23^{\prime} 46,8^{\prime} \mathrm{S} 48^{\circ} 24^{\prime} 56,3^{\prime} \mathrm{W}\end{array}$ & 475 & 2 & 14.x.2001 \\
\hline PG4 & $\begin{array}{l}\text { Município de Barretos, Fazenda Três Irmãos, Córrego da Guanabara } \\
\qquad 20^{\circ} 27^{\prime} 21,3 \text { ”S } 48^{\circ} 37^{\prime} 06,3^{\prime \prime} \mathrm{W}\end{array}$ & 526 & 2 & 07.x.2001 \\
\hline PG5 & $\begin{array}{l}\text { Município de Guaíra, Fazenda Santo Inácio, Córrego do Ambrósio } \\
20^{\circ} 11^{\prime} 49,7^{\prime} \mathrm{S} 48^{\circ} 33^{\prime} 11,6^{\prime} \mathrm{W}\end{array}$ & 462 & 2 & 13.x.2001 \\
\hline PG6 & $\begin{array}{l}\text { Município de Colômbia, Córrego da Batata } \\
20^{\circ} 14^{\prime} 10,2^{\prime} \mathrm{S} 48^{\circ} 40^{\prime} 42,0^{\prime \prime} \mathrm{W}\end{array}$ & 457 & 2 & 06.x.2001 \\
\hline SG1 & $\begin{array}{l}\text { Município de Santo Antônio da Alegria, riacho sem nome afluente direto do Rio Pinheiro ou Sapucaí } \\
\qquad 21^{\circ} 00^{\prime} 40,7^{\prime} \mathrm{S} 47^{\circ} 13^{\prime} 11,5^{\prime \prime} \mathrm{W}\end{array}$ & 705 & 1 & 27.iii.2002 \\
\hline SG2 & $\begin{array}{l}\text { Município de Altinópolis, Fazenda São José, Córrego Água do Pinheiro } \\
20^{\circ} 59^{\prime} 54,5^{\prime} \mathrm{S} 47^{\circ} 11^{\prime} 16,2^{\prime} \mathrm{W}\end{array}$ & 839 & 2 & 25.iii.2002 \\
\hline SG3 & $\begin{array}{l}\text { Município de Nuporanga, Fazenda Mangueira, Córrego do Arrozal } \\
20^{\circ} 40^{\prime} 57,0^{\prime} \mathrm{S} 47^{\circ} 40^{\prime} 18,4^{\prime \prime} \mathrm{W}\end{array}$ & 676 & 1 & 23.iii.2002 \\
\hline
\end{tabular}


SG4

SG5

SG6
Município de Guará, Córrego São José ou Bocainha $20^{\circ} 29^{\prime} 20,3$ 'S $47^{\circ} 45^{\prime} 46,8^{\prime \prime} \mathrm{W}$

Município de Guaíra, Fazenda do Cervo, Córrego do Cervo

$20^{\mathrm{a}} 15^{\prime} 24,3^{\prime \prime} \mathrm{S} 48^{\circ} 14^{\prime} 42,4^{\prime \prime} \mathrm{W}$

Município de Miguelópolis, Córrego do Matão

$20^{\circ} 11^{\prime} 50,4^{\prime \prime} \mathrm{S} 48^{\circ} 13^{\prime} 42,9^{\prime \prime} \mathrm{W}$
652

24. iii. 2002

513

121. iii. 2002

495

20.iii.2002 
Tabela 2. Fisiografia, dados fisico-químicos, transparência horizontal da água, composição granulométrica predominante da amostra de fundo no ponto médio (cf. Cummins, 1962) e vegetação do entorno nos 18 trechos de riachos amostrados na bacia do rio Grande, SP, nas Unidades de Gerenciamento de Recursos Hídricos (UGRHI) do Turvo-Grande (TG), Baixo Pardo-Grande (PG) e Sapucaí-Grande (SG), todas da bacia do Rio Grande, São Paulo.

\begin{tabular}{|c|c|c|c|c|c|c|c|c|c|c|}
\hline Trechos & $\begin{array}{l}\text { Variação da } \\
\text { largura (m) }\end{array}$ & $\begin{array}{c}\text { Variação da } \\
\text { profundidade (m) }\end{array}$ & $\begin{array}{l}\text { Velocidade da } \\
\text { corrente }\left(\mathrm{m}^{-1} \mathrm{~s}^{-1}\right)\end{array}$ & $\begin{array}{c}\text { Temperaturas } \\
\text { do ar e da } \\
\text { água }\left({ }^{\circ} \mathrm{C} /{ }^{\circ} \mathrm{C}\right)\end{array}$ & pH & $\begin{array}{c}\text { Oxigênio } \\
\text { dissolvido } \\
\left(\mathrm{mg.l}^{-1}\right) \\
\end{array}$ & $\begin{array}{l}\text { Condutividade } \\
\left(\mu \mathrm{S} . \mathrm{cm}^{-1}\right)\end{array}$ & $\begin{array}{l}\text { Transparência } \\
\text { horizontal (m) }\end{array}$ & $\begin{array}{c}\begin{array}{c}\text { Granulometria } \\
\text { dominante do } \\
\text { substrato }\end{array} \\
\end{array}$ & $\begin{array}{c}\text { Vegetação } \\
\text { do } \\
\text { entorno } \\
\end{array}$ \\
\hline TG1 & $4,8-6,2$ & $0,01-0,80$ & 0,26 & $15,5 / 19,1$ & 8,40 & 9,6 & 69,9 & 1,0 & $\begin{array}{l}\text { areia média e } \\
\text { areia fina }\end{array}$ & plantio \\
\hline TG2 & $1,9-4,3$ & $0,04-0,56$ & 0,32 & $16,3 / 20,0$ & 8,40 & 9,6 & 84,1 & 1,0 & $\begin{array}{l}\text { grânulo e areia } \\
\text { fina }\end{array}$ & $\begin{array}{c}\text { pastagem e } \\
\text { canavial }\end{array}$ \\
\hline TG3 & $1,2-1,6$ & $0,07-0,51$ & 0,30 & $18,6 / 15,2$ & 8,09 & 9,0 & 26,1 & 1,0 & $\begin{array}{l}\text { areia média e } \\
\text { areia fina }\end{array}$ & canavial \\
\hline TG4 & $1,4-1,9$ & $0,05-0,28$ & 0,14 & $19,9 / 16,9$ & 8,24 & 11,2 & 25,4 & 1,5 & $\begin{array}{l}\text { areia média e } \\
\text { areia fina }\end{array}$ & canavial \\
\hline TG5 & $1,1-2,0$ & $0,04-0,32$ & 0,45 & $20,4 / 16,7$ & 7,88 & 10,2 & 87,5 & 1,8 & $\begin{array}{l}\text { areia média e } \\
\text { areia fina }\end{array}$ & pastagem \\
\hline TG6 & $0,8-2,3$ & $0,01-0,50$ & 0,08 & $17,2 / 15,7$ & 7,36 & 5,8 & 190,0 & 1,0 & $\begin{array}{l}\text { areia grossa e } \\
\text { areia média }\end{array}$ & pastagem \\
\hline PG1 & $1,2-1,5$ & $0,12-0,46$ & $\sim 0$ & $27,5 / 21,7$ & 8,41 & 5,8 & 135,4 & 0,8 & $\begin{array}{l}\text { grânulo e areia } \\
\text { muito grossa }\end{array}$ & pastagem \\
\hline PG2 & $1,0-1,4$ & $0,16-0,89$ & 2,0 & $23,3 / 23,8$ & 7,60 & 2,6 & 68,3 & 1,2 & $\begin{array}{c}\text { grânulo e areia } \\
\text { média }\end{array}$ & plantio \\
\hline PG3 & $0,9-2,8$ & $0,14-0,53$ & 0,50 & $26,0 / 22,5$ & 8,21 & 4,7 & 70,1 & 0,9 & $\begin{array}{l}\text { areia média e } \\
\text { areia fina }\end{array}$ & plantio \\
\hline PG4 & $0,8-1,3$ & $0,09-0,36$ & 0,23 & $26,7 / 25,6$ & 8,20 & 10,3 & 8,3 & 0,8 & $\begin{array}{l}\text { areia grossa e } \\
\text { areia média }\end{array}$ & pastagem \\
\hline PG5 & $1,1-2,2$ & $0,65-1,05$ & 0,18 & $35,8 / 25,7$ & 7,86 & 6,1 & 41,5 & 0,2 & $\begin{array}{l}\text { grânulo e areia } \\
\text { fina }\end{array}$ & pastagem \\
\hline PG6 & $2,0-3,0$ & $0,07-0,29$ & 0,38 & $24,0 / 22,5$ & 8,01 & 7,8 & 28,4 & 0,4 & $\begin{array}{l}\text { saibro e areia } \\
\text { fina }\end{array}$ & pastagem \\
\hline SG1 & $1,9-3,5$ & $0,02-0,49$ & 0,39 & $24,3 / 22,5$ & 8,56 & 8,2 & 22,5 & 0,8 & $\begin{array}{l}\text { areia fina e } \\
\text { areia muito fina }\end{array}$ & pastagem \\
\hline SG2 & $1,4-2,5$ & $0,03-0,32$ & 0,29 & $30,0 / 22,8$ & 8,40 & 9,2 & 10,3 & 0,3 & $\begin{array}{c}\text { areia fina e } \\
\text { grânulo }\end{array}$ & pastagem \\
\hline
\end{tabular}




\begin{tabular}{|c|c|c|c|c|c|c|c|c|c|c|}
\hline SG3 & $1,4-3,1$ & $0,05-0,50$ & 1,03 & $28,8 / 23,7$ & 8,21 & 8,8 & 17,8 & 0,6 & $\begin{array}{c}\text { cascalho } \\
\text { arenoso e } \\
\text { grânulo }\end{array}$ & pastagem \\
\hline SG4 & $3,5-4,0$ & $0,08-0,72$ & 1,34 & $27,1 / 23,8$ & 7,87 & 8,2 & 31,3 & 0,3 & $\begin{array}{l}\text { areia média e } \\
\text { areia grossa }\end{array}$ & pastagem \\
\hline SG5 & $2,2-2,7$ & $0,50-1,16$ & 0,54 & $24,8 / 24,2$ & 7,78 & 8,3 & 31,0 & 0,4 & $\begin{array}{l}\text { grânulo e areia } \\
\text { muito grossa }\end{array}$ & milharal \\
\hline SG6 & $1,6-4,5$ & $0,10-1,15$ & $\sim 0$ & $27,2 / 25,0$ & 7,80 & 9,8 & 60,0 & 0,1 & $\begin{array}{l}\text { grânulo e areia } \\
\text { muito grossa }\end{array}$ & canavial \\
\hline
\end{tabular}


Tabela 3. Descrição geral sucinta dos 18 trechos de riachos amostrados nas Unidades de Gerenciamento de Recursos Hídricos (UGRHI) do Turvo-Grande (TG), Baixo Pardo-Grande (PG) e Sapucai-Grande (SG), todas da bacia do Rio Grande, São Paulo.

Trechos Descrição

TG 1 Traçado bastante sinuoso; margens com declividade acentuada e barrancos de até 4 m de altura, com alternância de poços fundos, remansos e corredeiras; margens com predominância de "samambaias" da família Pteridaceae (Adianthum sp.) e "lírios-do-brejo" da família Zingiberiaceae (Hedychium sp.).

TG 2 Traçado pouco sinuoso; margens quase planas, sem declividade, com alternância de remansos e corredeiras; margens com predominância de "lírios-dobrejo" da família Zingiberiaceae (Hedychium sp.) e "capins" da família Poaceae (e.g. Leersia sp.).

TG 3 Traçado pouco sinuoso; margens com declividade acentuada, formando desníveis de 8 a 12 m de altura, fortemente encaixado, com pequenas quedas d'água; margens com predominância de Melastomataceae e "capins" das famílias Cyperaceae (Rhynchospora aurea Vahl) e Poaceae.

TG 4 Traçado moderadamente sinuoso; margens com declividade acentuada formadas por degraus de até $90 \mathrm{~cm}$ de altura, alternando poços rasos e corredeiras suaves; margens com predominância de Pteridophyta (família Pteridaceae), Melastomataceae e "capins” da família Cyperaceae (Rhynchospora aurea Vahl).

TG 5 Traçado pouco sinuoso; margens com declividade acentuada, com barrancos de até 2 m de altura, com alternância de corredeiras e remansos; margens alagadas, com predominância, nas áreas abertas, de macrófitas aquáticas das famílias Pontederiaceae (Eichhornia sp.), Najadaceae (cf. Najas sp.) e Onagraceae (Ludwigia sp.).

TG 6 Traçado moderadamente sinuoso; margens com declividade acentuada (até $90^{\circ}$ ), com barrancos de 0,5 a $1,5 \mathrm{~m}$ de altura, com pequenas corredeiras rasas; margens com predominância das famílias Piperaceae (Piper sp.), Cyperaceae (Rhynchospora aurea Vahl) e Zingiberiaceae (Hedychium sp.).

PG 1 Traçado pouco sinuoso; margens lamacentas e pouco íngremes; margens com predominância das famílias Heliconiaceae (Heliconia sp.) e Cyperaceae (Rhynchospora aurea $\mathrm{Vahl}$ ).

PG 2 Traçado sinuoso; margens com pouca declividade, sem barrancos pronunciados, com predomínio de corredeiras; margens com predominância das famílias Piperaceae (Piper sp.), Melastomataceae e Zingiberiaceae (Hedychium sp.).

PG 3 Traçado pouco sinuoso; margens com declividade acentuada, quase retas, com alternância de poços e corredeiras; margens repletas de "trapoerabas" da família Commelinaceae (Commelina sp.) e “capins” da família Poaceae.

PG 4 Trecho pouco sinuoso; margens com barrancos íngremes, de até $3 \mathrm{~m}$ de altura, com predomínio de corredeiras; margens com predominância de pteridófitas (samambaiaçus). das famílias Piperaceae (Piper sp.) e Melastomataceae. 
PG 5 Traçado moderadamente sinuoso; margens com barrancos íngremes, de até 0,5 m de altura, com alternância de poços e corredeiras encaixadas; margens repletas de "trapoerabas" da família Commelinaceae (Commelina sp.) e "capins" da família Poaceae.

PG 6 Traçado moderadamente sinuoso; margens com barrancos íngremes, com alternância de poços fundos e corredeiras; margens com predominância de macrófitas das famílias Pontederiaceae (Heteranthera cf. reniformis) e Commelinaceae (Commelina sp.), além de muitas plântulas de Inga sp. (Leguminosae-Mimosoidea).

SG 1 Traçado pouco sinuoso; margens com barrancos suaves, de até $40^{\circ}$ de inclinação, com alternância de corredeiras e pequenos poços; margens repletas de "lírios-do-brejo" (Hedychium sp.) da família Zingiberiaceae e "pimenteiras" da família Piperaceae (Piper cf. tuberculatum Jacq. e Peperonia sp.).

SG 2 Traçado moderadamente sinuoso; margens com barrancos íngremes, de até $50^{\circ}$ de inclinação e até 1,8 metro de altura, com pequenas corredeiras; margens com predominância de "quaresmeiras" da família Melastomataceae e "bambus" da família Poaceae, com pequenos grupos de avencas (Pteridophyta) junto aos barrancos úmidos.

SG 3 Trecho sinuoso; margens altas, verticais, com até $1 \mathrm{~m}$ de altura, com alternância de poços e corredeiras; margens repletas de "quaresmeiras" (Melastomataceae) e "pimenteiras" da família Piperaceae (Piper cf. tuberculatum Jacq. e Peperonia sp.).

SG 4 Trecho moderadamente sinuoso; margens variando desde pequenas praias a barrancos suaves com até $30^{\circ}$ de inclinação, com predominância de corredeiras moderada e pequenos poços; margens com predominância de "lírios-do-brejo" (Hedychium sp.) da família Zingiberiaceae, "trapoerabas" da família Commelinaceae (Commelina sp.) e "capins" da família Cyperaceae.

SG 5 Traçado pouco sinuoso; margens com barrancos íngremes com até 90 de inclinação e 1,5 m de altura, sem poços, com corredeiras moderadas; margens com predominância das famílias Poaceae e Thelypteridaceae, com extrato arbóreo baixo e ralo, formado na sua maioria por sangra d’água (Croton urucurana).

SG 6 Traçado moderadamente sinuoso; margens com até 2,5 m de altura, com pequena extensão de corredeiras; margens com predominância de "capins" da família Poaceae, e "ingás" (Leguminosae-Mimosoidea) do gênero Inga. 
Tabela 4. Dez espécies mais abundantes nos trechos de riacho estudados na bacia do Rio Grande, São Paulo, com suas respectivas guildas tróficas, distribuições espaciais e fontes bibliográficas utilizadas para efetuar essa classificação.

\begin{tabular}{|c|c|c|c|}
\hline Espécies & GuildasTróficas & $\begin{array}{l}\text { Distribuições } \\
\text { Espaciais }\end{array}$ & Fontes Bibliográficas \\
\hline $\begin{array}{l}\text { Astyanax altiparanae, Astyanax scabripinnis, Astyanax } \\
\text { fasciatus, Hemigrammus marginatus e Piabina argentea }\end{array}$ & Onivoras & Nectônicas & $\begin{array}{l}\text { Ushirohira (1970), Godoy (1975), Soares (1979), Schroeder- } \\
\text { Araujo (1980), Obara \& Mendes (1990), Esteves \& Galetti } \\
\text { (1995), Esteves (1996), Castro \& Casatti (1997), Uieda et } \\
\text { al., (1997), Casatti \& Castro (1998) e Ferreira (2002). }\end{array}$ \\
\hline Characidium zebra & Invertívora & Bentônica & $\begin{array}{l}\text { Sabino \& Castro (1990), Castro \& Casatti (1997), Casatti \& } \\
\text { Castro (1998). }\end{array}$ \\
\hline Serrapinnus heterodon & Algívora & Necto-bentônica & Casatti et al., (2003). \\
\hline Hypostomus ancistroides e Hisonotus sp. & Perifitívoras & Bentônicas & $\begin{array}{l}\text { Uieda (1984), Power (1984a, 1984b, 1990), Lowe- } \\
\text { McConnel (1987), Costa (1987), Teixeira (1989), Obara \& } \\
\text { Mendes (1990), Silva (1993), Arcifa \& Mesquiatti (1993), } \\
\text { Buck \& Sazima (1995), Uieda et al., (1997), Castro \& } \\
\text { Casatti (1998), Luiz et al., (1998), Sabino \& Zuanon (1998), } \\
\text { Aranha et al., 1998), Sabino (2000), Casatti et al., (2001) e } \\
\text { Ferreira (2002). }\end{array}$ \\
\hline Geophagus brasiliensis & Onívora & Bentônica & Sabino \& Castro (1990). \\
\hline
\end{tabular}


Tabela 5. Lista taxonômica das 64 espécies de peixes coletadas nos 18 trechos de riachos estudados nas Unidades de Gerenciamento de Recursos Hídricos (UGRHI) do Turvo-Grande (TG), Baixo Pardo-Grande (PG) e Sapucaí-Grande (SG), todas da bacia do Rio Grande, São Paulo. A classificação segue Reis et al. (2002).

Ordem Characiformes

Família Erythrinidae

Família Lebiasinidae

Hoplerythrinus unitaeniatus (Agassiz, 1829)

Hoplias malabaricus (Bloch, 1794)

Família Characidae

Pyrrhulina australis Eigenmann \& Kennedy, 1903

Incertae Sedis

Astyanax altiparanae Garutti \& Britski, 2000

Astyanax fasciatus (Cuvier, 1819)

Astyanax scabripinnis (Jenyns, 1842)

Astyanax sp.

Bryconamericus stramineus (Eigenmann, 1908)

Bryconamericus sp.

Gymnocorymbus ternetzi (Boulenger, 1895)

Hemigrammus marginatus (Ellis, 1911)

Hemigrammus sp.

Hyphessobrycon anisitsi (Eigenmann, 1907)

Hyphessobrycon eques (Steindachner, 1882)

Moenkhausia intermedia Eigenmann, 1908

Moenkhausia sanctaefilomenae (Steindachner, 1907)

Oligosarcus pintoi Campos, 1945

Piabina argentea Reinhardt, 1866

Subfamília Cheirodontinae

Serrapinnus heterodon (Eigenmann, 1915)

Serrapinnus notomelas (Eigenmann, 1915)

Subfamília Glandulocaudinae

Planaltina britskii

Subfamília Myleinae

Família Crenuchidae

Metynnis mola Eigenmann \& Kennedy, 1903

Characidium gomesi Travassos, 1956

Characidium cf. lagosantense Travassos, 1947

Characidium zebra Eigenmann, 1909

Família Curimatidae

Steindachnerina insculpta (Fernández-Yepez, 1948)

Família Anostomidae

Leporinus friderici (Bloch, 1794)

Leporinus lacustris Campos, 1945

Leporinus striatus Kner, 1859

Família Parodontidae

Apareiodon affinis (Steindachner, 1879)

Apareiodon ibitiensis Campos, 1944

Parodon nasus Kner, 1859

Ordem Siluriformes

Família Heptapteridae

Cetopsorhamdia iheringi Schubart \& Gomes, 1959

Imparfinis schubarti (Gomes, 1956)

Pimelodella sp.

http://www.biotaneotropica.org.br 
Rhamdia quelen (Quoy \& Gaimard, 1824)

Família Pimelodidae

Phenacorhamdia tenebrosa (Schubart, 1964)

Família Trichomycteridae

Pimelodus maculatus LaCepède, 1803

Família Callichthyidae

Trichomycterus brasiliensis Reinhardt, 1873

Subfamília Callichthyinae

Lepthoplosternum pectorale (Boulenger, 1895)

Megalechis personata (Ranzani, 1841)

Subfamília Corydoradinae

Aspidoras fuscoguttatus Nijssen \& Isbrücker, 1756

Corydoras aeneus (Gill, 1858)

Família Loricariidae

Subfamília Hypoptopomatinae

Hisonotus insperatus Britski \& Garavello, 2003

Hisonotus sp.

Subfamília Loricariinae

Rineloricaria latirostris (Boulenger, 1900)

Subfamília Hypostominae

Hypostomus ancistroides (Ihering, 1911)

Hypostomus nigromaculatus (Schubart, 1964)

Hypostomus sp.

Ordem Gymnotiformes

Família Sternopygidae

Família Gymnotidae

Eigenmannia virescens (Valenciennes, 1847)

Gymnotus cf. carapo Linnaeus, 1758

Gymnotus cf. inaequilabiatus (Valenciennes, 1842)

Gymnotus cf. sylvius Albert \& Fernandes-Matioli, 1999

Ordem Cyprinodontiformes

Família Poeciliidae

Phalloceros caudimaculatus (Hensel, 1868)

Poecilia reticulata Peters, 1859

Família Rivulidae

Rivulus pictus Costa, 1989

Ordem Synbranchiformes

Família Synbranchidae

Synbranchus marmoratus Bloch, 1795

Ordem Perciformes

Família Cichlidae

Subfamília Cichlasomatinae

Cichlasoma facetum (Jenyns, 1842)

Cichlasoma paranaense Kullander, 1983

Subfamília Cichlinae

Cichla monoculus Spix \& Agassiz, 1831

Crenicichla britskii Kullander, 1982

Crenicichla haroldoi Luengo \& Britskii, 1974

Subfamília Geophaginae

Geophagus brasiliensis (Quoy \& Gaimard, 1824)

Satanoperca pappaterra (Heckel, 1840) 
Tabela 6a. Número total de indivíduos coletados (N), amplitude do comprimento padrão (CP) em mm, e biomassa total (BM) em gramas dos peixes coletados nos trechos de riachos de números 1 a 6 da Unidade de Gerenciamento de Recursos Hidricos (UGRHI) do Turvo-Grande (TG), da bacia do Rio Grande, São Paulo.

\begin{tabular}{|c|c|c|c|c|c|c|c|c|c|c|c|c|c|c|c|c|c|c|}
\hline Trechos & & TG1 & & & TG2 & & & TG3 & & & TG4 & & & TG5 & & & TG6 & \\
\hline Espécies & $\mathbf{N}$ & $\mathbf{C P}$ & BM & $\mathbf{N}$ & $\mathbf{C P}$ & BM & $\mathbf{N}$ & $\mathbf{C P}$ & BM & $\mathbf{N}$ & $\mathbf{C P}$ & BM & $\mathbf{N}$ & $\mathbf{C P}$ & BM & $\mathbf{N}$ & $\mathbf{C P}$ & BM \\
\hline Apareiodon affinis & - & - & - & - & - & - & - & - & - & - & - & - & 1 & 62,3 & 4,5 & - & - & - \\
\hline Aspidoras fuscoguttatus & - & - & - & 1 & 26,0 & 0,5 & 36 & $14-8-37,2$ & 20,5 & 15 & $12,3-35,8$ & 8,0 & 46 & $16,4-37,3$ & 32,0 & 4 & $25,5-33,4$ & 3,0 \\
\hline Astyanax altiparanae & 2 & $50,6-60,1$ & 12,0 & - & - & - & 103 & $34,4-83,3$ & 520,0 & 26 & $52,9-84,3$ & 283,5 & 70 & $44,4-75,1$ & 505,5 & 158 & $42,1-104,5$ & 1132,5 \\
\hline Astyanax fasciatus & 6 & $50,1-50,7$ & 28,0 & - & - & - & - & - & - & - & - & - & 1 & 69,1 & 8,0 & 4 & $47,7-57,6$ & 13,5 \\
\hline Astyanax scabripinnis & - & - & - & - & - & - & 34 & $17,8-54,9$ & 36,5 & 6 & $47,7-62,8$ & 24,0 & 3 & $36,7-49,7$ & 7,0 & - & - & - \\
\hline Bryconamericus stramineus & - & - & - & 22 & $7,5-52,3$ & 14,5 & - & - & - & - & - & - & - & - & - & - & - & - \\
\hline Characidium gomesi & 8 & $29,4-51,9$ & 12,0 & - & - & - & - & - & - & - & - & - & - & - & - & - & - & - \\
\hline Characidium zebra & 3 & $49,7-50,3$ & 8,5 & 1 & 67,1 & 5,5 & 36 & $27,2-51,1$ & 39,5 & 8 & $35,1-56,7$ & 13,0 & 2 & $31,5-31,9$ & 1,0 & - & - & - \\
\hline Cichlasoma paranaense & - & - & - & 5 & $48,5-67,8$ & 53,5 & 4 & $34,6-77,6$ & 64,0 & - & - & - & 4 & $44,2-72,3$ & 47,5 & - & - & - \\
\hline Corydoras aeneus & - & - & - & 1 & 37,5 & 2,5 & - & - & - & - & - & - & - & - & - & - & - & - \\
\hline Crenicichla britskii & - & - & - & 2 & $30,8-94,2$ & 21,5 & - & - & - & - & - & - & - & - & - & - & - & - \\
\hline Crenicichla haroldoi & - & - & - & 5 & $56,5-109,5$ & 52,0 & - & - & - & - & - & - & - & - & - & - & - & - \\
\hline Eigenmannia virescens & 1 & 174,0 & 18,0 & - & - & - & - & - & - & - & - & - & - & - & - & - & - & - \\
\hline Geophagus brasiliensis & - & - & - & 1 & 68,0 & 11,5 & - & - & - & - & - & - & - & - & - & 1 & 67,5 & 11,5 \\
\hline Gymnotus cf. carapo & 1 & 123,1 & 6,5 & - & - & - & - & - & - & - & - & - & - & - & - & - & - & - \\
\hline Gymnotus cf. sylvius & - & - & - & 16 & $95,0-240,0$ & 251,0 & - & - & - & - & - & - & - & - & - & 2 & $94,2-98,7$ & 7,5 \\
\hline Hisonotus insperatus & - & - & - & 37 & $18,7-27,9$ & 10,5 & - & - & - & - & - & - & - & - & - & - & - & - \\
\hline Hoplias malabaricus & - & - & - & - & - & - & - & - & - & - & - & - & 1 & 180,3 & 124,5 & - & - & - \\
\hline Hyphessobrycon eques & - & - & - & - & - & - & - & - & - & - & - & - & - & - & - & 3 & $20,8-29,3$ & 1,0 \\
\hline Hypostomus ancistroides & 4 & $29,6-54,0$ & 12,0 & 22 & $32,2-78,1$ & 110,0 & 8 & $20,0-79,2$ & 46,0 & 15 & $20,4-66,7$ & 22,0 & 23 & $21,0-65,5$ & 61,0 & 4 & $35,1-43,3$ & 6,0 \\
\hline Hypostomus sp. & 1 & 98,5 & 23,0 & 6 & $35,8-79,7$ & 35,5 & - & - & - & - & - & - & 30 & $24,2-88,4$ & 65,0 & - & - & - \\
\hline Imparfinis schubarti & 7 & $58,8-85,2$ & 37,5 & 1 & 96,7 & 17,5 & - & - & - & - & - & - & - & - & - & - & - & - \\
\hline Leporinus striatus & 8 & $75,6-104,1$ & 106,0 & - & - & - & - & - & - & - & - & - & - & - & - & 5 & $53,5-59,3$ & 19,0 \\
\hline Moenkhausia sanctaefilomenae & - & - & - & - & - & - & - & - & - & - & - & - & - & - & - & 1 & 37,4 & 2,5 \\
\hline Oligosarcus pintoi & - & - & - & 2 & $58,4-71,1$ & 12,5 & - & - & - & - & - & - & - & - & - & 1 & 44,5 & 2,0 \\
\hline Parodon nasus & - & - & - & 5 & $63,6-84,8$ & 41,5 & 4 & $38,5-40,0$ & 4,5 & - & - & - & 15 & $40,8-71,1$ & 46,5 & - & - & - \\
\hline
\end{tabular}


Phalloceros caudimaculatus Phenacorhamdia tenebrosa

Piabina argentea

Pimelodella sp.

Planaltina britskii

Poecilia reticulata

Rhamdia quelen

Rineloricaria latirostris

Serrapinnus heterodon

Serrapinnus notomelas

Synbranchus marmoratus

Totais $\begin{array}{ccc}- & - & - \\ 27,2 & 0,5 & -\end{array}$

$23,9-54,9 \quad 25,0 \quad 36 \quad 37,1-58,7 \quad 70,0$

$48,8-89,9 \quad 36,5$

$\begin{array}{lllll}33,3 & 0,5 & 2 & 24,5-29,0 & 1,0\end{array}$

$22 \quad 11,6-21,7 \quad 3,5 \quad 1$

$51,0 \quad 2,0$

$9,5 \quad 0,5$

59,6-147,2 27,5

$\begin{array}{lll}1 & - & -\end{array}$

97

$$
132,3
$$


Tabela $6 b$. Número total de indivíduos coletados (N), amplitude do comprimento padrão (CP) em mm, e biomassa total (BM) em gramas dos peixes coletados nos trechos de riachos de números 1 a 6 da Unidade de Gerenciamento de Recursos Hídricos (UGRHI) do Baixo Pardo-Grande (PG), da bacia do Rio Grande, São Paulo.

\begin{tabular}{|c|c|c|c|c|c|c|c|c|c|c|c|c|c|c|c|c|c|c|}
\hline \multirow{2}{*}{$\begin{array}{l}\text { Trechos } \\
\text { Espécies }\end{array}$} & \multicolumn{3}{|c|}{ PG1 } & \multicolumn{3}{|c|}{ PG2 } & \multicolumn{3}{|c|}{ PG3 } & \multicolumn{3}{|c|}{ PG4 } & \multicolumn{3}{|c|}{ PG5 } & \multicolumn{3}{|c|}{ PG6 } \\
\hline & $\mathbf{N}$ & $\mathbf{C P}$ & BM & $\mathbf{N}$ & $\mathbf{C P}$ & BM & $\mathbf{N}$ & $\mathbf{C P}$ & BM & $\mathbf{N}$ & $\mathbf{C P}$ & BM & $\mathbf{N}$ & $\mathbf{C P}$ & BM & $\mathbf{N}$ & $\mathbf{C P}$ & BM \\
\hline Astyanax altiparanae & 45 & $37,7-101,4$ & 596,5 & - & - & - & 20 & $50,2-97,4$ & 253,5 & - & - & - & 7 & $35,5-68,7$ & 27,5 & 68 & $58,2-113,6$ & 1514,5 \\
\hline Astyanax fasciatus & - & - & - & - & - & - & 4 & $65,3-80,0$ & 35,0 & - & - & - & - & - & - & - & - & - \\
\hline Astyanax scabripinnis & - & - & - & 10 & $37,8-66,9$ & 51,5 & - & - & - & 21 & $19,2-70,5$ & 87,5 & - & - & - & - & - & - \\
\hline Characidium gomesi & - & - & - & - & - & - & - & - & - & - & - & - & - & - & - & 8 & $36,9-48,0$ & 12,0 \\
\hline Characidium cf. lagosantensis & - & - & - & - & - & - & - & - & - & - & - & - & 2 & $26,3-28,2$ & 1,0 & - & - & - \\
\hline Characidium zebra & - & - & - & 3 & $64,7-73,2$ & 25,0 & 1 & 42,9 & 2,0 & 1 & 24,5 & 0,5 & 71 & $21,7-51,2$ & 50,0 & - & - & - \\
\hline Cichlasoma facetum & 35 & $42,9-79,5$ & 448,0 & - & - & - & - & - & - & - & - & - & - & - & - & - & - & - \\
\hline Cichlasoma paranaense & - & - & - & - & - & - & 2 & $53,5-66,0$ & 26,0 & - & - & - & - & - & - & 2 & $80,8-97,9$ & 81 \\
\hline Corydoras aeneus & 1 & 39,4 & 3,0 & - & - & - & - & - & - & - & - & - & - & - & - & - & - & - \\
\hline Eigenmannia virescens & - & - & - & - & - & - & 1 & 165,0 & 10,0 & - & - & - & 3 & $98,3-116,9$ & 53,0 & - & - & - \\
\hline Geophagus brasiliensis & 31 & $43,1-97,8$ & 468,0 & - & - & - & 2 & $104,0-120,0$ & 111,0 & 69 & $27,5-53,9$ & 199,0 & - & - & - & - & - & - \\
\hline Gymnotus cf. sylvius & - & - & - & 2 & $132,1-150,1$ & 41,0 & 1 & 188,2 & 23,5 & - & - & - & - & - & - & 1 & 122,3 & 6,5 \\
\hline Hemigrammus marginatus & 4 & $28,2-31,2$ & 2,5 & - & - & - & - & - & - & - & - & - & 244 & $17,1-34,1$ & 117,5 & - & - & - \\
\hline Hoplerithrynus unitaeniatus & - & - & - & - & - & - & 1 & 191,0 & 202,5 & - & - & - & 4 & $138,0-188,0$ & 450,0 & - & - & - \\
\hline Hoplias malabaricus & 3 & $66,7-140,3$ & 52,0 & - & - & - & - & - & - & - & - & - & 2 & $96,7-106,4$ & 28,0 & 1 & 151,2 & 90,5 \\
\hline Hyphessobrycon anisitsi & 5 & $29,2-37,2$ & 5,0 & - & - & - & - & - & - & - & - & - & - & - & - & - & - & - \\
\hline Hyphessobrycon eques & - & - & - & - & - & - & 6 & $24,8-29,9$ & 4,5 & - & - & - & 25 & $24,3-30,2$ & 17,5 & - & - & - \\
\hline Hypostomus ancistroides & 5 & $66,2-98,3$ & 74,0 & 11 & $36,8-57,3$ & 38,0 & - & - & - & - & - & - & 8 & $14,6-66,0$ & 14,0 & 6 & $17,1-45,7$ & 8,0 \\
\hline Imparfinis schubarti & - & - & - & - & - & - & 2 & $80,4-89,9$ & 20,0 & - & - & - & 5 & $54,7-80,2$ & 24,0 & 3 & $54,2-64,9$ & 10,0 \\
\hline Leporinus friderici & - & - & - & - & - & - & - & - & - & - & - & - & - & - & - & 1 & 143,4 & 73,5 \\
\hline Leporinus lacustris & - & - & - & - & - & - & - & - & - & - & - & - & 1 & 41,3 & 8,0 & - & - & - \\
\hline Leporinus striatus & - & - & - & - & - & - & - & - & - & - & - & - & - & - & - & 1 & 81,6 & 11,0 \\
\hline Lepthoplosternum pectorale & - & - & - & - & - & - & - & - & - & - & - & - & - & - & - & 4 & $35,2-53,6$ & 18,0 \\
\hline Megalechis personata & - & - & - & - & - & - & - & - & - & - & - & - & - & - & - & 1 & 55,1 & 7,0 \\
\hline Metynnis mola & - & - & - & - & - & - & - & - & - & - & - & - & 1 & 65,3 & 3,5 & - & - & - \\
\hline Moenkhausia intermedia & - & - & - & - & - & - & - & - & - & - & - & - & 28 & $37,0-57,1$ & 81,5 & - & - & - \\
\hline
\end{tabular}

http://www.biotaneotropica.org.br 


\begin{tabular}{|c|c|c|c|c|c|c|c|c|c|c|c|c|c|c|c|c|c|c|}
\hline Oligosarcus pintoi & 24 & $26,7-91,5$ & 434,5 & - & - & - & - & - & - & - & - & - & - & - & - & - & - & - \\
\hline Piabina argentea & - & - & - & - & - & - & - & - & - & - & - & - & - & - & - & 15 & $32,8-53,9$ & 24,5 \\
\hline Pimelodus maculatus & - & - & - & - & - & - & - & - & - & - & - & - & - & - & - & 6 & $87,7-101,8$ & 111,0 \\
\hline Pyrrhulina australis & - & - & - & - & - & - & - & - & - & - & - & - & - & - & - & 5 & $26,3-34,4$ & 35,5 \\
\hline Rhamdia quelen & 6 & $100,6-141,3$ & 191,0 & 1 & 17,1 & 0,5 & - & - & - & - & - & - & - & - & - & - & - & - \\
\hline Rivulus pictus & - & - & - & - & - & - & - & - & - & - & - & - & - & - & - & 1 & 25,5 & 0,5 \\
\hline Serrapinnus heterodon & 6 & $26,2-35,3$ & 4,5 & - & - & - & 104 & $16,8-29,1$ & 32,0 & - & - & - & 69 & $19,8-27,4$ & 32,5 & - & - & - \\
\hline Serrapinnus notomelas & - & - & - & - & - & - & - & - & - & - & - & - & 85 & $23,6-29,4$ & 43,0 & - & - & - \\
\hline Synbranchus marmoratus & 2 & $154,1-155,7$ & 11,5 & - & - & - & - & - & - & - & - & - & - & - & - & - & - & - \\
\hline Totais & 167 & & 2290,5 & 27 & & 156,0 & 144 & & 720,0 & 91 & & 287,0 & 555 & & 951,0 & 123 & & 2003,5 \\
\hline
\end{tabular}


Tabela 6c. Número total de indivíduos coletados (N), amplitude do comprimento padrão (CP) em mm, e biomassa total (BM) em gramas dos peixes coletados nos trechos de riachos de números 1 a 6 da Unidade de Gerenciamento de Recursos Hídricos (UGRHI) do Sapucai-Grande (SG), da bacia do Rio Grande, São Paulo.

\begin{tabular}{|c|c|c|c|c|c|c|c|c|c|c|c|c|c|c|c|c|c|c|}
\hline \multirow{2}{*}{$\begin{array}{l}\text { Trechos } \\
\text { Espécies }\end{array}$} & \multicolumn{3}{|c|}{ SG1 } & \multicolumn{3}{|c|}{ SG2 } & \multicolumn{3}{|c|}{ SG3 } & \multicolumn{3}{|c|}{ SG4 } & \multicolumn{3}{|c|}{ SG5 } & \multicolumn{3}{|c|}{ SG6 } \\
\hline & $\mathbf{N}$ & $\mathbf{C P}$ & BM & $\mathbf{N}$ & $\mathbf{C P}$ & BM & $\mathbf{N}$ & $\mathbf{C P}$ & BM & $\mathbf{N}$ & $\mathbf{C P}$ & BM & $\mathbf{N}$ & $\mathbf{C P}$ & BM & $\mathbf{N}$ & $\mathbf{C P}$ & BM \\
\hline Apareiodon affinis & - & - & - & - & - & - & - & - & - & - & - & - & - & - & - & 1 & 38,9 & 0,5 \\
\hline Apareiodon ibitiensis & - & - & - & - & - & - & 1 & 87,3 & 11,5 & 6 & $49,7-110,9$ & 98,0 & - & - & - & - & - & - \\
\hline Astyanax altiparanae & 3 & $26,3-48,7$ & 9,5 & - & - & - & - & - & - & - & - & - & - & - & - & 32 & $13,0-99,1$ & 144,0 \\
\hline Astyanax fasciatus & 102 & $15,2-31,8$ & 30,5 & - & - & - & 6 & $67,6-87,1$ & 72,5 & 14 & $69,7-106,9$ & 258,5 & 4 & $31,9-50,0$ & 9,5 & 11 & $12,0-35,9$ & 5,0 \\
\hline Astyanax scabripinnis & 1 & 30,9 & 0,5 & 69 & $16,8-80,8$ & 92,5 & 1 & 76,7 & 15,5 & 36 & $16,2-65,1$ & 56,5 & - & - & - & - & - & - \\
\hline Astyanax sp. & 20 & $35,8-70,8$ & 108,0 & 3 & $32,8-39,4$ & 4,0 & 18 & $36,7-84,9$ & 145,0 & - & - & - & - & - & - & - & - & - \\
\hline Bryconamericus sp. & - & - & - & - & - & - & 1 & 48,8 & 3,0 & - & - & - & & & & & & \\
\hline Bryconamericus stramineus & - & - & - & - & - & - & - & - & - & 3 & $47,6-50,7$ & 6,0 & - & - & - & - & - & - \\
\hline Cetopsorhamdia iheringi & - & - & - & - & - & - & 2 & $59,5-64,2$ & 10,5 & 16 & $30,1-67,0$ & 42,0 & - & - & - & 1 & 14,5 & 0,5 \\
\hline Characidium zebra & 7 & $41,3-58,3$ & 13,0 & 5 & $43,5-58,2$ & 15,0 & 1 & 48,9 & 1,5 & 8 & $29,2-61,8$ & 20,5 & - & - & - & 3 & $15,5-21,8$ & 1,0 \\
\hline Cichla monoculus & - & - & - & - & - & - & - & - & - & - & - & - & - & - & - & 1 & 107,0 & 28,0 \\
\hline Crenicichla haroldoi & - & - & - & - & - & - & - & - & - & - & - & - & - & - & - & 4 & $73,1-136,7$ & 119,0 \\
\hline Eigenmannia virescens & - & - & - & - & - & - & - & - & - & 23 & $29,5-173,9$ & 153,0 & - & - & - & - & - & - \\
\hline Geophagus brasiliensis & 6 & $31,5-72,2$ & 47,5 & - & - & - & - & - & - & - & - & - & 4 & $40,0-130,2$ & 179,0 & 8 & $57,7-117,0$ & 231,0 \\
\hline Gymnocorymbus ternetzi & - & - & - & - & - & - & - & - & - & - & - & - & - & - & - & 2 & $19,6-23,6$ & 1,0 \\
\hline Gymnotus cf. inaequilabiatus & - & - & - & - & - & - & - & - & - & - & - & - & - & - & - & 3 & $166,3-295,4$ & 136,0 \\
\hline Gymnotus cf. sylvius & 2 & $110-136,3$ & 15,5 & - & - & - & 5 & $80,6-175,5$ & 32,0 & - & - & - & - & - & - & 8 & $64,3-158,1$ & 40,0 \\
\hline Hemigrammus marginatus & - & - & - & - & - & - & - & - & - & - & - & - & - & - & - & 1 & 34,0 & 0,5 \\
\hline Hemigrammus sp. & - & - & - & - & - & - & - & - & - & - & - & - & - & - & - & 1 & 21,9 & 0,5 \\
\hline Hisonotus sp. & - & - & - & - & - & - & - & - & - & 144 & $12,9-32,0$ & 43,5 & - & - & - & - & - & - \\
\hline Hoplias malabaricus & - & - & - & - & - & - & - & - & - & - & - & - & 1 & $112-4$ & 34,5 & 2 & $68,3-117,5$ & 45,0 \\
\hline Hyphessobrycon eques & - & - & - & - & - & - & - & - & - & - & - & - & - & - & - & 43 & $11,0-23,3$ & 9,5 \\
\hline Hypostomus ancistroides & 2 & $56,3-56,5$ & 10,5 & - & - & - & 13 & $40,5-77,2$ & 58,5 & 139 & $11,1-72,3$ & 327,0 & 8 & $14,9-83,3$ & 21,0 & 8 & $19,5-78,0$ & 54,0 \\
\hline Hypostomus sp. & - & - & - & - & - & - & - & - & - & - & - & - & - & - & - & 1 & 99,0 & 32,5 \\
\hline Hypostomus nigromaculatus & - & - & - & - & - & - & - & - & - & 10 & $18,1-60,7$ & 30,0 & - & - & - & - & - & - \\
\hline Imparfinis schubarti & - & - & - & - & - & - & 8 & $73,3-79,6$ & 58,5 & - & - & - & - & - & - & 10 & $11,9-26,8$ & 2,0 \\
\hline Leporinus friderici & - & - & - & - & - & - & - & - & - & - & - & - & - & - & - & 2 & $21,1-24,9$ & 5,5 \\
\hline
\end{tabular}

http://www.biotaneotropica.org.br 
Megalechis personata

Metynnis mola

Oligosarcus pintoi

Phalloceros caudimaculatus

Piabina argentea

Pimelodella sp.

Poecilia reticulata

Rhamdia quelen

Rineloricaria latirostris

Satanoperca pappaterra

Serrapinnus heterodon

Serrapinnus notomelas

Steindachnerina insculpta

Trichomycterus brasiliensis

Totais

\section{3,0-53,9 7,0}

- $\quad-$

$-$

$49 \quad 24,1-44,1 \quad 33,5 \quad-$$$
\text { - }
$$$$
\text { - - }
$$$$
1 \quad 105,6 \quad 23,5
$$$$
1 \quad 139,9 \quad 22,0
$$$$
75,3-77,9
$$

$32,1-78,8$

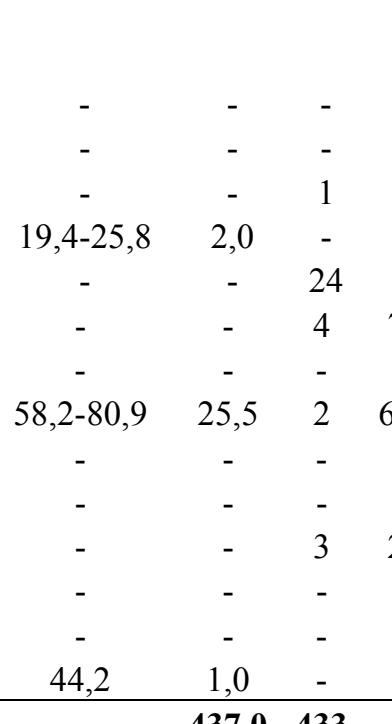

$437,0 \quad 433$

$$
59,2
$$

-

$79,3-95,9$

-

68,7-104,8 29,5 -

-

27,3-30,9
$21,1-24,9$

$69,7 \quad 17,0$

$26,2 \quad 0,5$

$1,8-28,1 \quad 1,0$

- $\quad-$

$97,7-128,0 \quad 278,0$

$23,5 \quad 0,5$

$20,8 \quad 0,5$

24,6-34,0 1,5

$\begin{array}{cccc}- & - & - & 33 \\ 208 & & 383,5 & 122\end{array}$

$24,1-89,2$

$\begin{array}{cc}75,5 & 1 \\ \mathbf{2 0 8 , 5} & \mathbf{6 7}\end{array}$

1154,5 
Tabela 7. Riqueza absoluta (S), diversidade teórica máxima (LogS), índice de diversidade de ShannonWienner $\left(H^{\prime}\right)$ e de Simpson (D) e Eqüitabilidade (e) para os 18 trechos de riachos das Unidades de Gerenciamento de Recursos Hídricos (UGRHI) do Turvo-Grande (TG), Baixo Pardo-Grande (PG) e Sapucai-Grande (SG), todas da bacia do Rio Grande, São Paulo.

\begin{tabular}{lccccc}
\hline Trechos & S & LogS & H'$^{\prime}$ & D & e \\
\hline TG 1 & 16 & 1,20 & 0,99 & 0,14 & 0,82 \\
TG 2 & 19 & 1,28 & 0,96 & 0,14 & 0,75 \\
TG 3 & 8 & 0,90 & 0,65 & 0,28 & 0,72 \\
TG 4 & 6 & 0,78 & 0,67 & 0,24 & 0,86 \\
TG 5 & 13 & 1,11 & 0,79 & 0,21 & 0,71 \\
TG 6 & 13 & 1,11 & 0,39 & 0,67 & 0,35 \\
Total TG & 37 & 1,57 & 1,06 & 0,17 & 0,67 \\
PG 1 & 12 & 1,08 & 0,85 & 0,18 & 0,79 \\
PG 2 & 5 & 0,70 & 0,56 & 0,32 & 0,80 \\
PG 3 & 11 & 1,04 & 0,46 & 0,54 & 0,44 \\
PG 4 & 3 & 0,48 & 0,26 & 0,63 & 0,54 \\
PG 5 & 15 & 1,18 & 0,76 & 0,25 & 0,64 \\
PG 6 & 15 & 1,18 & 0,73 & 0,33 & 0,62 \\
Total PG & 35 & 1,54 & 1,10 & 0,11 & 0,71 \\
SG 1 & 13 & 1,11 & 0,68 & 0,31 & 0,61 \\
SG 2 & 6 & 0,78 & 0,51 & 0,33 & 0,65 \\
SG 3 & 13 & 1,11 & 0,93 & 0,15 & 0,84 \\
SG 4 & 15 & 1,18 & 0,81 & 0,23 & 0,68 \\
SG 5 & 5 & 0,70 & 0,61 & 0,28 & 0,87 \\
SG 6 & 26 & 1,41 & 1,08 & 0,14 & 0,76 \\
Total SG & 41 & 1,61 & 1,20 & 0,09 & 0,74 \\
\hline
\end{tabular}


comprimento padrão na bacia do Rio Grande, juntamente com a presença de somente $0,5 \%$ de indivíduos da mesma classe de tamanho coletados por Castro et al. (2003a), no Rio Paranapanema, reforçam mais uma vez a hipótese de Castro (1999) de que a predominância de peixes de pequeno porte é o único padrão geral de valor diagnóstico registrado até o momento para a ictiofauna de riachos sul-americanos. Ainda na mesma linha, a recomendação de Castro \& Menezes (1998) no sentido de priorizar a exploração científica de ambientes de riachos e cabeceiras no Estado de São Paulo é aqui também reforçada pelo fato de, das 64 espécies coletadas, quatro ( $6 \%$ do total) serem seguramente novas e oito (12\% do total) possuírem status taxonômico ainda indefinido, perfazendo assim um total de $18 \%$ de espécies coletadas pouco ou nada conhecidas cientificamente.

Considerando todos os trechos amostrados na bacia do Rio Grande, as espécies com os maiores números de indivíduos foram $A$. altiparanae e $H$. ancistroides, e aquelas com a maior biomassa foram $A$. altiparanae e $G$. brasiliensis. A dominância ecológica de $A$. altiparanae nos riachos do Rio Grande (17,4\% do total de indivíduos coletados e 35\% da biomassa total) também ocorreu nos 17 riachos do Rio Paranapanema estudados por Castro et al. (2003a), onde $A$. altiparanae representou $15,2 \%$ e $28 \%$ do total de indivíduos coletados e da biomassa, respectivamente, o que, de modo geral, reflete os resultados obtidos por Uieda (1984), Garutti (1988), Penczak et al. (1994), Pavanelli \& Caramaschi (1997) e Castro \& Casatti (1997).

As razões para a dominância ecológica de $A$. altiparanae neste tipo de ambiente podem ser várias; porém, como pode ser visto abaixo, a espécie em questão faz parte da guilda dos onívoros, o que claramente deve torná-la capaz de adaptar-se de maneira ótima às ofertas alimentares diferenciais tanto do ponto de vista geográfico quanto sazonal. Além disso, é uma espécie nectônica, nadadora rápida, muito pouco dependente de esconderijos dentre os micro-hábitats bentônicos para evitar predação (ver Casatti, 2002), sendo também uma espécie extremamente plástica quanto às suas estratégias reprodutivas, apresentando desovas parceladas durante todo o ano em pequenos corpos d'água como os riachos estudados e desova total em grandes corpos d'água (Garutti, 1989), sem apresentar cuidado parental (Agostinho \& Júlio Jr., 1999), com ovos flutuantes (Godoy, 1975), relativamente independente portanto do substrato para reprodução. Tal estratégia reprodutiva, combinada com sua grande amplitude trófica, deve ser extremamente vantajosa do ponto de vista ecológico nos riachos estudados, considerando que o principal impacto antrópico deletério em tais localidades é, aparentemente, o assoreamento. Tais perturbações são conseqüência da transformação (muitas vezes incluindo grande parte da floresta ciliar) da cobertura vegetal original em pastagens ou cultivos, levando à perda física de importantíssimos micro-hábitats bentônicos.
Dentre as cinco guildas tróficas identificadas neste estudo, quatro são idênticas àquelas encontradas por Castro et al. (2003a) na bacia do Rio Paranapanema, reforçando a suposição de que provavelmente ambas as bacias possuem a mesma macro organização de nichos ecológicos alimentares típica do sistema do Alto Rio Paraná. Tal fato indica que, tanto na bacia do Rio Grande (presente trabalho), quanto na do Rio Paranapanema (Castro et al., 2003a), os trechos escolhidos, apesar de impactados em graus variados, ainda devem reter a maior parte de sua complexidade ecossistêmica original.

Dentre os onívoros nectônicos, os principais itens alimentares autóctones ingeridos são larvas aquáticas de insetos, principalmente Chironomidae, e dentre os itens alóctones destacam-se as formigas (Castro \& Casatti, 1997; Casatti \& Castro, 1998; Ferreira, 2002). A espécie dominante, A. altiparanae, forma cardumes de 20 a 50 indivíduos que nadam à meia-água coletando partículas arrastadas pela corrente. Durante a noite, os indivíduos permanecem estacionários nos poços mais profundos dos riachos, mas ocasionalmente podem capturar insetos que caem na água, vindos da vegetação ripária (Casatti, 2002). De acordo com Castro et al. (2003a), na bacia do Rio Paranapanema os onívoros nectônicos representaram uma fração praticamente idêntica (40\%) do total de indivíduos coletados.

A guilda dos invertívoros bentônicos, que inclui apenas Characidium zebra (Figura 4b: 25), representou uma fração $50 \%$ menor do que aquela encontrada nos riachos da bacia do Rio Paranapanema (13,6\%), onde a mesma foi composta por três espécies de Siluriformes (Pimelodella sp., Corydoras aeneus e Imparfinis mirini) (Castro et al., 2003a), que têm como principal tática alimentar - como é comum para diversas espécies de Siluriformes - , a especulação do substrato, utilizando primariamente seus barbilhões sensoriais tácteis e quimioreceptores na busca de itens alimentares em substratos não consolidados. Characidium zebra, um caraciforme desprovido de barbilhões como os siluriformes, utiliza, além da especulação do substrato, a tática de espreita onde a orientação visual é de fundamental importância (Sazima, 1986; Sabino \& Castro, 1990). Nesta guilda, os itens alimentares principais são autóctones, com predominância de larvas aquáticas de insetos (Castro \& Casatti, 1997).

Não há informações publicadas de nosso conhecimento sobre as táticas alimentares de Serrapinnus heterodon, a única espécie incluída na guilda dos algívoros. Porém, Casatti et al. (2003) descreveram um comportamento de Serrapinnus notomelas onde os adultos organizam-se em grupos pequenos e mordiscam ("nibblers", cf. Sazima, 1986) tufos de algas próximos às raízes de macrófitas em águas rasas. Tanto na Represa de Rosana, um ambiente lêntico, quanto em dois riachos também da bacia do Rio Paranapanema, a mesma espécie alimentou-se 
principalmente de algas, tomadas da superfície de macrófitas submersas ou semi-submersas no primeiro caso (Casatti et al., 2003), e provavelmente junto ao fundo no segundo caso (Luiz et al., 1998).

Quanto aos perifitívoros, os mesmos, nos 17 riachos estudados por Castro et al. (2003a) na bacia do Rio Paranapanema, apresentaram importância percentual praticamente idêntica àquela encontrada no presente estudo $(13,6 \%)$, com a diferença que houve uma inversão da importância relativa das espécies: Hisonotus sp. é mais abundante que $H$. ancistroides (Castro et al., 2003a). É de conhecimento geral (ver Power, 1990) que indivíduos das espécies da subfamília Hypoptopomatinae, tal como Hisonotus sp., alimentam-se aderidos à vegetação marginal submersa por suas ventosas bucais e odontóides retroversos dos primeiros raios de suas nadadeiras pélvicas, enquanto $H$. ancistroides, um Hypostominae, é mais freqüentemente observada no fundo dos riachos (Casatti et al., 2001; Casatti, 2002). Nesta guilda, o alimento ingerido geralmente consiste de algas e protozoários associados à matéria orgânica, juntamente com sedimento, que compõem a matriz perifítica encontrada sobre substratos submersos (Uieda et al., 1997).

Assim como nos riachos do Paranapanema estudados por Castro et al. (2003a), os onívoros bentônicos estão representados unicamente por G. brasiliensis (Figura 7: 7), com a diferença de haverem sido encontrados em menor número relativo de indivíduos: $4 \%$ no Rio Grande, versus 7,8\% no Rio Paranapanema (Castro et al., 2003a). Nesta guilda, a tática alimentar é a coleta de substrato e separação de presa ("diggers of localized excavations", cf. Sazima, 1986), durante a qual o sedimento abocado pelo peixe é expelido pela boca e aberturas operculares e os itens alimentares, retidos e ingeridos (Sabino \& Castro, 1990). Geralmente o alimento ingerido compreende larvas aquáticas de insetos, algas e detritos (Sabino \& Castro, 1990).

Tal como já dito por Castro \& Casatti (1997) com relação às espécies de Astyanax com ampla distribuição geográfica ocorrendo na bacia do Alto Rio Paraná, também consideramos que a espécie aqui denominada como Astyanax scabripinnis consiste num complexo de formas, a maioria das quais provavelmente merecedoras de status específico. Até que o grupo seja revisto, achamos prudente manter o nome pelo qual tal complexo de espécies é mais conhecido na região sudeste. As razões para Gymnocorymbus ternetzi ter sido considerada como tendo quase certamente sido introduzida na bacia do Alto Rio Paraná baseiam-se na combinação do fato de Benine (2000), em sua revisão do gênero Gymnocorymbus, somente ter encontrado em coleções material de G. ternetzi proveniente de uma única localidade da bacia em questão, da bacia do Rio Mogi-Guaçu (Lagoa do Diogo, Estação Ecológica de Jataí), onde pode ter sido introduzida (uma vez que é uma espécie muito comum no comércio de peixes ornamentais), com G. ternetzi sequer constar da lista de Agostinho \& Júlio Jr. (1999) dos peixes do segmento brasileiro da bacia do Rio Paraná. Apesar de considerarmos impossível neste momento definir com precisão razoável se Hoplerythrinus unitaeniatus, Hyphessobrycon eques e Satanoperca pappaterra são espécies introduzidas ou nativas, algumas considerações são pertinentes. Apesar da impossibilidade atual de distinguir taxonomicamente as populações de Hyphessobrycon eques das bacias dos Rios Paraná-Paraguai eAmazonas (cf. Weitzman \& Palmer, 1997: 145), por existirem casos similares envolvendo espécies de Characiformes de pequeno porte (cf. Garutti \& Britski, 2000), é possível supor que a espécie da bacia do Alto Rio Paraná venha revelar-se nova, ou pelo menos distinta das populações de Hyphessobrycon eques da bacia Amazônica, que contém a localidade tipo da espécie. A presença natural simultânea de Hoplerythrinus unitaeniatus na bacia do Alto Rio Paraná e na bacia do Rio São Francisco, de onde a espécie foi descrita (Oyakawa, 2003), também não seria implausível, uma vez que ambas as drenagens em questão, juntamente com a do Alto Paraíba do Sul e toda uma série de drenagens costeiras do leste do Brasil, compartilham uma história evolutiva comum (Castro et al., 2003b). Além disso, a distribuição comum ao Alto Rio Paraná e Alto Rio São Francisco de Corydoras difluviatilis (cf. Britto \& Castro, 2002) reforça ainda mais tal possibilidade. Quanto a ocorrência de Santanoperca pappaterra, descrita do Rio Guaporé, bacia Amazônica (Kullander, 2003), acreditamos ser possivelmente conseqüência da introdução dessa espécie na bacia do Alto Rio Paraná.

A curva de acumulação do número de espécies em função do número de indivíduos coletados (Figura 10) mostra que a assíntota ainda não foi atingida (ver Castro \& Casatti, 1997 para discussão detalhada da eficiência relativa das diferentes metodologias de coleta empregadas em combinação). Como já foi dito nos resultados, apesar de termos coletado 64 espécies, a estimativa de riqueza por extrapolação para o conjunto total de riachos amostrados na bacia do Rio Grande indica um valor de 93 espécies (erro padrão igual a três). Tal diferença, estimada em 29 espécies, pode ser atribuída ao elevado número de espécies raras na amostra (27), visto que os algoritmos envolvidos na estimativa em questão extraem as informações sobre as classes não encontradas principalmente das classes raras na amostra (Cowell, 1997). Portanto, apesar das diferenças entre o estimado e o obtido, é nossa opinião que os retratos instantâneos da estrutura e composição das ictiocenoses amostradas são fiéis, tendo sido nossa metodologia de coleta, em conseqüência, adequada aos fins propostos. 
6. Chave de identificação para as 64 espécies de peixes coletadas nos 18 trechos de riachos amostrados na bacia do Rio Grande, SP, nas Unidades de Gerenciamento de Recursos Hídricos (UGRHI) do Turvo-Grande (TG), Baixo Pardo-Grande (PG) e Sapucaí-Grande (SG).

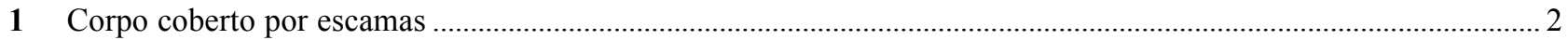

1' Corpo desprovido de escamas ou coberto por placas ósseas …...................................................................................... 47

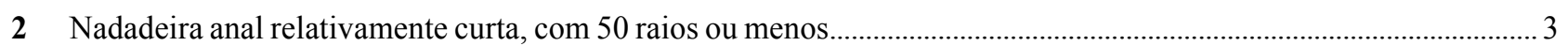

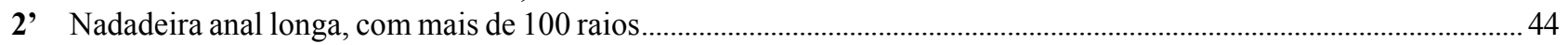

3 Machos com nadadeira anal não transformada em estrutura copuladora (gonopódio)................................................. 4

3' Machos com a nadadeira anal transformada em estrutura copuladora (gonopódio) ................................................ 37

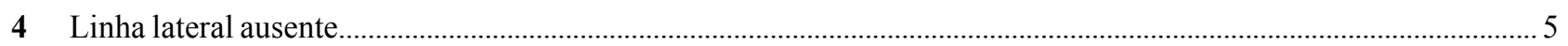

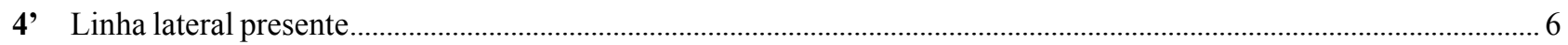

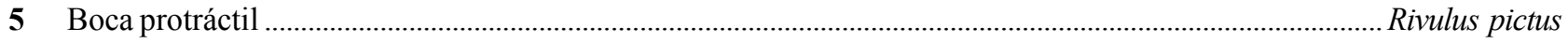

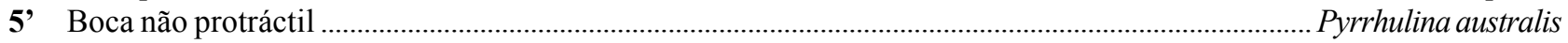

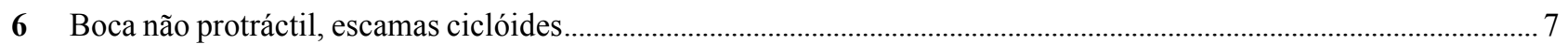

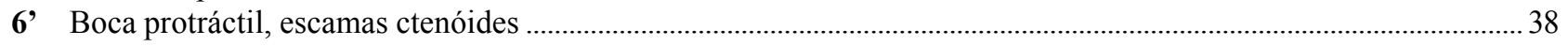

7 Nadadeira caudal dos machos com glândula de feromônio .................................................. Planaltina britskii (piaba)

7' Nadadeira caudal desprovida de glândula de feromônio ............................................................................................. 8

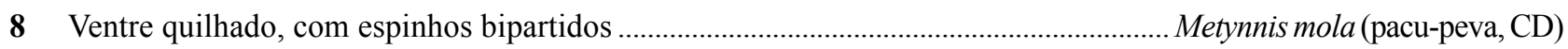

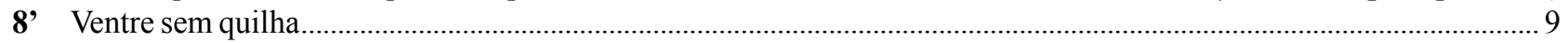

9 Dentes ausentes........................................................................................................ Steindachnerina insculpta (sagüiru)

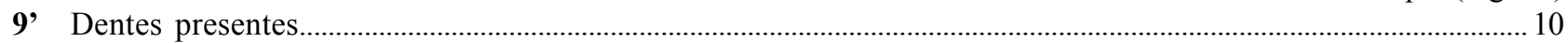

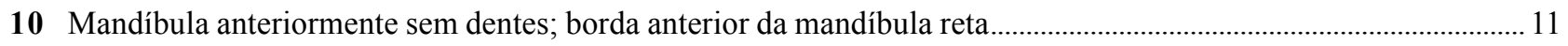

10' Mandíbula anteriormente com dentes; borda anterior da mandíbula arredondada.......................................................... 13

11 Mandíbula com 2 a 3 dentes posteriores

11' Mandíbula totalmente desprovida de dentes

12 Flanco com manchas verticalmente ovaladas

Apareiodon ibitiensis (canivete)

12' Flanco sem manchas verticalmente ovaladas. Apareiodon affinis (canivete)

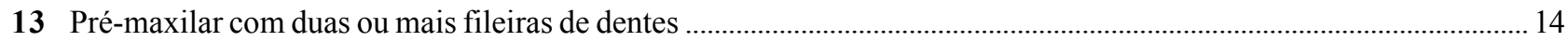

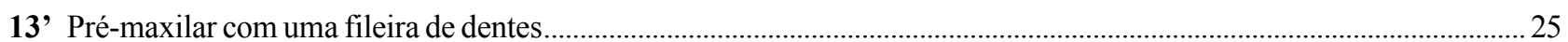

14 Pré-maxilar com cinco dentes na fileira interna e com disposição regular dos dentes da fileira externa ...................... 15

14' Pré-maxilar com quatro dentes na fileira interna e com disposição irregular dos dentes da fileira externa .............. 35

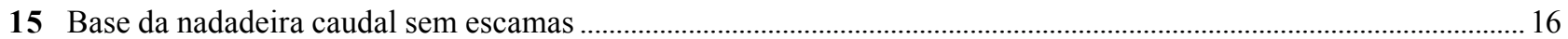

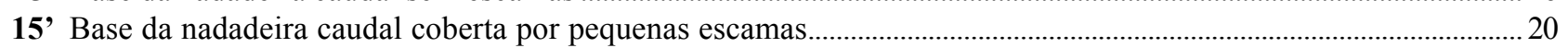

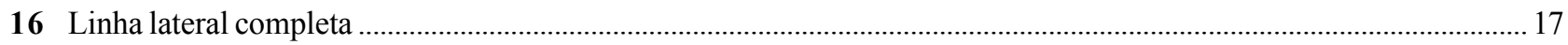

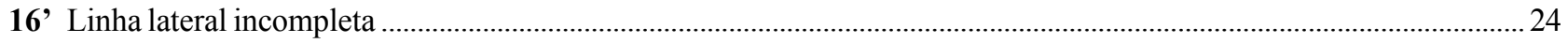

http://www.biotaneotropica.org.br 
17 Osso maxilar desprovido de dentes, mancha umeral de contorno bem definido, e horizontalmente ovalada; nadadeira caudal amarela em vida . Astyanax altiparanae (lambari-do-rabo-amarelo)

17. Osso maxilar com um ou mais dentes, mancha umeral com contorno difuso, e verticalmente alongada; nadadeira caudal de coloração hialina-amarelada, alaranjada, rosada ou vermelha em vida..

18 Altura do corpo contida de 2,2 a 2,9 (mais comumente 2,5) vezes no comprimento padrão; mancha umeral verticalmente alongada, pouco difusa, quase sempre seguida de área escura posterior difusa porém claramente visível; nadadeira caudal rosada ou avermelhada em vida; nadadeira anal com 22 a 26 raios (mais comumente 25) Astyanax sp. (lambari)

18 Altura do corpo contida de 2,6 a 3,3 vezes no comprimento padrão; mancha umeral verticalmente alongada, difusa e geralmente única; quando muito seguida de área enegrecida uniforme e difusa posterior

19 Nadadeira caudal vermelha em vida; sem manchas escuras difusas na porção dorso-lateral do corpo; nadadeira anal geralmente com 24 a 30 raios (mais comumente 25 a 27) Astyanax fasciatus (lambari-do-rabo-vermelho)

19' Nadadeira caudal geralmente rosada ou alaranjada em vida; manchas escuras difusas na porção dorso-lateral do corpo; nadadeira anal geralmente com 18 a 23 raios (mais comumente 21)..Astyanax scabripinnis (lambari-de-cabeceira)

20 Linha lateral incompleta

20' Linha lateral completa.

21 Nadadeira caudal com sua margem negra

Hemigrammus marginatus (piaba)

21' Nadadeira caudal hialina. Hemigrammus sp. (piaba)

22 Linha mediana pré-dorsal nua ou irregularmente escamada; 7 a 8 séries de escamas acima e abaixo da linha lateral, 38 a 42 raios ramificados na nadadeira anal Gymnocorymbus ternetzi (tetra-preto)

22' Linha mediana pré-dorsal regularmente escamada, até 5 séries de escamas acima da linha lateral e 3 séries de escamas abaixo da linha lateral; 19 a 24 raios ramificados na nadadeira anal

23 Sem mancha negra conspícua no pedúnculo caudal; ausência de um padrão reticulado de coloração do corpo; faixa prateada no flanco do corpo; lobos superior e inferior da nadadeira caudal com uma mancha negra não atingindo a margem posterior da nadadeira; base e extremidades posteriores da nadadeira caudal e raio não ramificado da pélvica brancos Moenkhausia intermedia (lambari-corintiano)

23'Mancha negra conspícua no pedúnculo caudal, padrão reticulado de coloração do corpo, sem faixa prateada no flanco do corpo, nadadeiras caudal e pélvicas hialinas Moenkhausia sanctaefilomenae (olho-de-fogo, lambari)

24 Nadadeira dorsal hialina Hyphessobrycon anisitsi (piquira, piaba)

24' Nadadeira dorsal com uma mácula negra conspícua. Hyphessobrycon eques (mato-grosso)

25 Nadadeira peitoral com 3 raios simples (não ramificados) anteriores 26

25' Nadadeira peitoral com 1 raio simples (não ramificado) anterior.

26 Istmo nu (desprovido de escamas); 12 escamas em torno do pedúnculo caudal

26' Istmo com escamas; 14 escamas em torno do pedúnculo caudal.

Characidium gomesi (canivete)

27 Pseudotímpano presente; 13 a 14 faixas estreitas no flanco; mancha no pedúnculo caudal bem definida. ................................................................................................................ Characidium cf. lagosantense (canivete)

27' Pseudotímpano ausente; 9-10 faixas largas no flanco; mancha no pedúnculo caudal difusa

Characidium zebra (canivete)

28 Pseudotímpano presente. 
29 Mancha negra apenas cobrindo a porção medial da base da nadadeira caudal

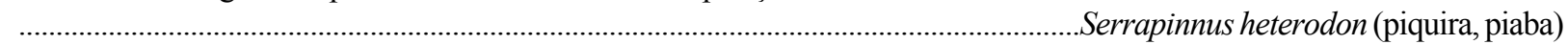

29' Uma mancha negra envolvendo todo o pedúnculo caudal.. Serrapinnus notomelas (piquira, piaba)

30 Dentes incisiviformes nas maxilas.

30' Dentes cônicos ou tricuspidados nas maxilas...

31 Quatro listras ao longo do corpo.. Leporinus striatus (piava, piau)

31' Sem listras ao longo do corpo.

3237 a 41 escamas na linha lateral; porte médio a grande Leporinus friderici (piau)

32' 33 a 35 escamas na linha lateral; porte pequeno Leporinus lacustris (piau)

33 Fontanela frontal ausente; nadadeira adiposa ausente 34

33' Fontanela frontal presente; nadadeira adiposa presente. Oligosarcus pintoi (lambari-cachorro)

34 Osso maxilar com dentes cônicos e caniniformes; porção superior do opérculo sem mácula negra conspícua Hoplias malabaricus (traíra)

34' Osso maxilar apenas com dentes cônicos, sem dentes caniniformes, porção superior do opérculo com uma mácula negra conspícua. Hoplerythrinus unitaeniatus (jeju)

35 Maxila superior mais longa que a inferior; porção denteada do pré-maxilar muito larga, dando a impressão de três séries de dentes

Piabina argentea (lambari, piaba)

35 Maxila superior tão longa quanto a inferior; porção denteada do pré-maxilar estreita, mostrando claramente duas séries de dentes, apesar da disposição irregular da série externa.....

36 Mancha umeral normalmente ausente; porção dorsal do corpo com uma faixa escura, muito estreita e inconspícua. Bryconamericus stramineus (piaba)

36' Mancha umeral sempre presente; porção dorsal do corpo com uma faixa escura, larga (pouco mais estreita que o diâmetro do olho) e conspícua. Bryconamericus sp. (piaba)

37 Fêmeas com coloração dos flancos e dorso castanho claro uniforme, ventre esbranquiçado e nadadeiras hialinas; machos com manchas esféricas negras e áreas de coloração viva variada nos flancos (principalmente metade posterior do corpo e nadadeira dorsal); gonopódio sem apêndice apical. Poecilia reticulata (güaru, lebiste)

37' Machos e fêmeas com padrão de cromatóforos escuros bordejando partes expostas das escamas formando um padrão geral reticulado sobre fundo castanho-claro; uma, ou mais raramente duas, manchas escuras verticalmente ovaladas na metade da altura do corpo, imediatamente abaixo ou um pouco atrás da terminação posterior da base da nadadeira dorsal; gonopódio com apêndice apical Phalloceros caudimaculatus (güaru, barrigudinho)

38 Ramo superior do primeiro arco branquial com lóbulo

38' Ramo superior do primeiro arco branquial sem lóbulo

39 Com mancha escura no meio do corpo. Geophagus brasiliensis (cará)

39' Sem mancha escura no meio do corpo. Satanoperca pappaterra (cará)

40 Corpo baixo (altura do corpo contida cerca de 3,3 a 4,4 vezes no comprimento padrão)

40' Corpo alto (altura do corpo contida cerca de 2,0 a 2,5 vezes no comprimento padrão).

41 Escamas pequenas; mais de 80 escamas na série longitudinal abaixo da linha lateral inferior; nadadeira caudal com borda posterior truncada ou côncava; borda posterior do pré-opérculo lisa Cichla monoculus (tucunaré)

41' Escamas de porte médio; menos de 65 escamas na série longitudinal abaixo da linha lateral inferior; nadadeira caudal com borda posterior convexa; borda posterior do pré-opérculo serrilhada . 
42 Mancha umeral presente; ocelo na base da nadadeira caudal presente Crenicichla britskii (joaninha)

42' Mancha umeral ausente; ocelo na base da nadadeira caudal ausente Crenicichla haroldoi (joaninha)

43 Tronco com mancha ovalada na porção mediana; com mancha na porção mediana do pedúnculo caudal; nadadeira anal com 7 a 8 espinhos Cichlasoma facetum (cará)

43 Tronco com mancha ovalada na porção mediana-dorsal; com mancha na porção mediana-dorsal do pedúnculo caudal; nadadeira anal com 3 espinhos. Cichlasoma paranaense (cará)

44 Mandíbula (dentários) situada no mesmo nível da extremidade anterior da maxila (pré-maxilares) ou levemente posterior (boca terminal ou sub-terminal)...

Eigenmannia virescens (tuvira)

44' Mandíbula (dentários) estendendo-se anteriormente além do nível da extremidade anterior da maxila (pré-maxilares) (boca prognata)

45 Região lateral do corpo apresentado bandas claras e escuras alternadas, com suas margens regulares 46

45' Região dorsal do corpo escura e porção ventro-lateral com bandas claras e escuras fragmentadas, formando um padrão de manchas irregulares. Gymnotus cf. inaequilabiatus (tuvira)

46 Corpo com bandas claras mais estreitas que as bandas escuras Gymnotus cf. carapo (tuvira)

46' Corpo com bandas escuras mais estreitas que as bandas claras Gymnotus cf. sylvius (tuvira)

47 Corpo coberto por placas ósseas. 48

47' Corpo nu, desprovido de placas ósseas.

48 Duas séries longitudinais de placas ósseas em cada lado do tronco; dois barbilhões em cada canto da boca; boca normal, sem aspecto de ventosa

48 Várias séries longitudinais de placas ósseas em cada lado do tronco; um barbilhão em cada canto da boca; boca com aspecto de ventosa.

49 Mandíbula com dentes; placa nucal coberta por pele (não exposta); focinho deprimido; barbilhão maxilar longo, usualmente estendendo-se além da abertura branquial ...

49' Mandíbula sem dentes; placa nucal exposta; focinho comprimido; barbilhão maxilar curto, usualmente não ultrapassando a margem posterior do olho...

50 Nadadeira dorsal com 1 espinho e 7 raios ramificados; nadadeira anal com 1 raio simples seguido de 5 raios ramificados.. Lepthoplosternum pectorale (tamoatá)

50' Nadadeira dorsal com 1 espinho, 1 raio simples e 7 a 8 raios ramificados; nadadeira anal com 2 raios simples e 5 a 6 raios ramificados. Megalechis personata (tamoatá)

51 Fontanela craniana pequena, arredondada; extremidade distal do primeiro raio da nadadeira peitoral com longa porção flexível (cerca de um terço do raio); região entre as bases das nadadeiras peitorais inteiramente coberta por pele; flanco com pequenas manchas dispersas Aspidoras fuscoguttatus (limpa-fundo)

51' Fontanela craniana alongada; extremidade distal do primeiro raio da nadadeira peitoral com curta porção flexível; coracóides expandidos no abdome entre as bases das nadadeiras peitorais; uma grande mancha irregular escura na porção anterior do flanco...... Corydoras aeneus (limpa-fundo)

52 Pedúnculo caudal deprimido, formando uma quilha de cada lado Rineloricaria latirostris (cascudo-lagartixa)

52' Pedúnculo caudal com seção transversal arredondada ou elíptica, sem formar quilhas laterais

53 Cintura escapular exposta, coberta com pequenos espinhos; adultos com porte pequeno (30 mm ou menos de comprimento padrão).

53' Cintura escapular não exposta, coberta com pele ou placas apenas; adultos com porte médio (50 mm ou mais de comprimento padrão). 
54 Ponta do focinho com uma única placa rostral; linha lateral interrompida no meio do corpo .... Hisonotus sp. (cascudinho) 54' Ponta do focinho com um par de placas rostrais; linha lateral contínua ao longo do corpo. Hisonotus insperatus (cascudinho)

55 Quilhas laterais no tronco presentes; corpo com pequenas pintas circulares Hypostomus ancistroides (cascudo)

55' Quilhas laterais no tronco ausentes; corpo sem pequenas pintas circulares

56 Espinho da nadadeira peitoral expandido na porção terminal e com espinhos (odontóides) hipertrofiados; corpo com grandes manchas irregulares, intercaladas por estreitas áreas claras Hypostomus nigromaculatus (cascudo)

56' Espinho da nadadeira peitoral não expandido na porção terminal e com pequenos espinhos (odontóides); corpo com amplas áreas claras

Hypostomus sp. (cascudo)

57 Corpo serpentiforme, uma única abertura branquial, mediana, localizada sob a cabeça; nadadeiras peitorais ausentes Synbranchus marmoratus (mussum)

57' Corpo não serpentiforme, um par de aberturas branquiais, localizadas ao longo das regiões lateral e ventral da cabeça; nadadeiras peitorais presentes.

58 Região

opercular

$\operatorname{com}$

espinhos

(odontóides)

direcionados

para trás... Trichomycterus brasiliensis (cambeva, bagrinho)

58' Região opercular sem espinhos (odontóides) 59

59 Primeiro raio das nadadeiras dorsal e peitoral quase totalmente rígido, formando um espinho

59' Primeiro raio das nadadeiras dorsal e peitoral flexível em mais da metade de seu comprimento, não formando um espinho

60 Corpo com três ou quatro séries longitudinais bem definidas de máculas escuras arredondadas, com reflexos amarelos quando o peixe está vivo; processo ósseo do cleitro (acima da nadadeira peitoral) muito evidente, de formato triangular Pimelodus maculatus (mandi)

60' Corpo sem séries longitudinais de máculas, com coloração parda quando o peixe está vivo; processo ósseo do cleitro (acima da nadadeira peitoral), quando presente, afilado

61 Tronco com coloração uniforme e com faixa escura conspícua ao longo da linha lateral; nadadeira caudal com lobos estreitos, de comprimento igual ou com o lobo superior levemente mais longo que o inferior; processo posterior do supra-occipital unido à nadadeira dorsal . Pimelodella sp. (mandi-chorão)

61' Tronco com manchas irregulares e sem uma faixa escura conspícua ao longo da linha lateral; nadadeira caudal com lobos largos, com o lobo inferior levemente mais longo que o superior; processo posterior do supra-occipital não atingindo a nadadeira dorsal. Rhamdia quelen (bagre, jundiá)

62 Dorso com barras transversais escuras; lobo caudal superior geralmente mais longo que o inferior. Imparfinis schubarti (bagrinho)

62' Dorso sem barras transversais escuras; lobo caudal inferior geralmente mais longo que o superior

63 Corpo curto e alto, altura do corpo contida cerca de 4,8 a 5,2 vezes no comprimento padrão; boca inferior; borda posterior das nadadeiras dorsal, peitoral, pélvica e anal truncada ou côncava Cetopsorhamdia iheringi (bagrinho)

63' Corpo longo e baixo, altura do corpo contida cerca de 7,2 a 9,2 vezes no comprimento padrão; boca prognata (i.e. mandíbula projetada para frente); borda posterior das nadadeiras dorsal, peitoral, pélvica e anal convexa Phenacorhamdia tenebrosa (bagrinho) 
7. Material das 64 espécies de peixes coletadas nos riachos da bacia do Rio Grande, SP, nas Unidades de Gerenciamento de Recursos Hídricos (UGRHI) do Turvo-Grande (TG), Baixo Pardo-Grande (PG) e Sapucaí-Grande (SG) e tombado na coleção ictiológica do Laboratório de Ictiologia de Ribeirão Preto (LIRP-USP), SP.

Apareiodon affinis: LIRP 2350, 3483; Apareiodon ibitiensis: LIRP 3498, 3507; Aspidoras fuscoguttatus: LIRP 2473, 2474, 2476, 2475, 2477; Astyanax altiparanae: LIRP 2917, 2915, 2877, 2913, 2901, 2914, 2916, 2907, 2902, 3474, 3530; Astyanax fasciatus: LIRP 2765, 2764, 2751, 2766, 3481, 3528, 3727, 3508, 3528; Astyanax scabripinnis: LIRP 2727 , 2728, 2733, 2724, 2732, 3505, 4008, 4007, 3522; Astyanax sp.: LIRP 3521, 3526, 3538; Bryconamericus stramineus: LIRP 2790, 3513; Bryconamericus sp.: LIRP 3503; Cetopsorhamdia iheringi: LIRP 3487, 3504, 3512; Characidium cf. lagosantense: LIRP 2506; Characidium gomesi: LIRP 2509; Characidium zebra: LIRP 2523, 2512 , 2522, 2532, 2536, 2520, 2516, 2517, 2515, 2535, 3496, 3516, 3523, 3534; Cichla monoculus: LIRP 3470; Cichlasoma facetum: LIRP 2595; Cichlasoma paranaense: LIRP 2599, 2601, 2606, 2604, 2596; Corydoras aeneus: LIRP 2546, 2551; Crenicichla britskii: LIRP 2584; Crenicichla haroldoi: LIRP 2593, 3476; Eigenmannia virescens: LIRP 2823, 2826, 2819, 3518; Geophagus brasiliensis: LIRP 2649, 2651, 2647, 2646, 2648, 3475, 3494, 3529; Gymnocorymbus ternetzi: LIRP 3490; Gymnotus cf. carapo: LIRP 2858; Gymnotus cf. sylvius: LIRP 2833, 2851, 2840, 2852, 2836, 3468, 3499, 3532; Gymnotus cf. inaequilabiatus: LIRP 3472; Hemigrammus marginatus: LIRP 2361, 2359, 3478; Hemigrammus sp.: LIRP 3480; Hisonotus insperatus: LIRP 2265; Hisonotus sp.: LIRP 3515; Hoplerithrynus unitaeniatus: LIRP 2329, 2328; Hoplias malabaricus: LIRP 2312, 2322, 2320, 2324, 3469, 3493; Hyphessobrycon anisitsi: LIRP 2371; Hyphessobrycon eques: LIRP 2380, 2378, 2377, 3484; Hypostomus ancistroides: LIRP 2689, 2684, 2696, 2713, 2714, 2693, 2721, 2698, 2681, 2720, 3471, 3492, 3501, 3506, 3535; Hypostomus nigromaculatus: LIRP 3226; Hypostomus sp.: LIRP 2673, 2667, 2665; Imparfinis schubarti: LIRP 2911, 2935, 2936, 2938, 2934, 3489, 3500; Leporinus friderici: LIRP 2335, 3482; Leporinus lacustris: LIRP 2337; Leporinus striatus: LIRP 2250, 2249, 2336; Lepthoplosternum pectorale: LIRP 2538; Megalechis personata: LIRP 2537, 3531; Metynnis mola: LIRP 2355, 3473; Moenkhausia intermedia: LIRP 2375; Moenkhausia sanctaefilomenae: LIRP 2387; Oligosarcus pintoi: LIRP 2409, 2400, 2403, 3510; Parodon nasus: LIRP 2366, 2370, 2635; Phalloceros caudimaculatus: LIRP 2615 , 3486, 3497; Phenacorhamdia tenebrosa: LIRP 2872; Piabina argentea: LIRP 2428, 2427, 2420, 3491, 3514, 3527; Pimelodella sp.: LIRP 2926, 3479, 3519; Pimelodus maculatus: LIRP 2393; Planaltina britskii.: LIRP 2257, 2256; Poecilia reticulata: LIRP 2633, 2634, 3511, 3520; Pyrrhulina australis: LIRP 2330; Rhamdia quelen: LIRP 2446, 2440, 2439, 2441, 2442, 2484, 3502, 3509, 3524, 3537; Rineloricaria latirostris: LIRP 2776, LIRP 3533; Rivulus pictus: LIRP 2609; Satanoperca pappaterra: LIRP 3477; Serrapinnus heterodon: LIRP 2489, 2484, 2488, 2487, 3517, 3539; Serrapinnus notomelas: LIRP 2496, 2493, 3488; Steindachnerina insculpta: LIRP 3485, 3536; Synbranchus marmoratus: LIRP 2568, 2574; Trichomycterus brasiliensis: LIRP 3495, 3525.

\section{Agradecimentos}

Somos gratos aos ictiólogos sistematas Heraldo A. Britski, Marcelo R. Britto, Ricardo Campos-da-Paz, Carlos A. A. de Figueiredo, Julio C. Garavello, Luiz R. Malabarba, Naércio A. Menezes, Osvaldo T. Oyakawa, Mario C. C. de Pinna, Richard P. Vari e Stanley H. Weitzman, pela ajuda na identificação dos peixes dos grupos de suas respectivas áreas de especialidade; a Jaqueline V. Bortolieiro pelo auxílio na digitação e organização dos dados no laboratório e a Sandra Raredon pelo auxílio na produção de radiografias digitais de algumas espécies; ao Instituto Brasileiro de Meio Ambiente e dos Recursos Naturais Renováveis (IBAMA), pela autorização de coleta e transporte de peixes concedida para a realização deste trabalho (autorização DIREN n ${ }^{\circ} 38 /$ 99, datada de 06.vii.1999); ao Neotropical Lowland Research Program of the International Sciences Program of the Smithsonian Institution, E.U.A., pelo auxílio financeiro e suporte durante as visitas técnicas do primeiro autor à Division of Fishes do National Museum of Natural History da mesma instituição; ao Research Training Program do National Museum of Natural History do Smithsonian Institution, por ter recebido ACR e MC e capacitado os mesmos a resolver importantes questões sistemáticas pertinentes à este trabalho; e finalmente, ao Departamento de Biologia da F.F.C.L.R.P. - Universidade de São Paulo, pelo apoio oferecido durante a realização deste trabalho. Este trabalho foi financiado pela Fundação de Amparo à Pesquisa do Estado de São Paulo (FAPESP) dentro do Programa BIOTASP/ FAPESP - O Instituto Virtual da Biodiversidade (www.biota.org.br) - através do Projeto Temático "Diversidade de peixes de riachos e cabeceiras da bacia do Alto Rio Paraná no Estado de São Paulo, Brasil/Fish diversity of the headwaters and streams of the upper Paraná River system in the State of São Paulo, Brazil" (FAPESP n ${ }^{\circ}$ 98/05072-8) e também pelo Projeto PRONEX “Conhecimento, Conservação e Utilização Racional da Diversidade da Fauna de Peixes do Brasil" (FINEP/CNPqn ${ }^{\circ}$ 661058/1997-2). RMCC e FL são bolsistas de pesquisa (CNPq n n's 301309/1991-4 e 300474/1999-7); LC é jovem pesquisadora (FAPESP n ${ }^{\circ} \mathrm{s}$ 01/ 13340-7 e 02/05996-2), foi bolsista de pós-doutoramento (FAPESP n ${ }^{\circ} 00 / 01919-8$ ) e doutoramento (FAPESP n ${ }^{\circ} 96 /$ 03286-5); ACR é bolsista de doutoramento (CNPq n ${ }^{\circ}$ 140488/ 04-9); TXA foi bolsista de doutoramento (FAPESP n ${ }^{\circ}$ 98/ 
12552-6); KMF, RCB, GZP e FZG são bolsistas de doutoramento (FAPESPn ${ }^{\circ}$ s 02/05464-0, 00/01920-6, 01/007809 e 00/06722-8); KMF e ALAM foram bolsistas de mestrado (FAPESP n ${ }^{\circ}$ s 00/01918-1 e 99/03852-9); MC foi bolsista de iniciação científica (FAPESP n $\left.{ }^{\circ} 02 / 00873-0\right)$ e é bolsista de mestrado (FAPESP n ${ }^{\circ}$ 03/04397-0); RS foi bolsista de capacitação técnica (nível I) e de iniciação científica (FAPESP n's 98/5072-8 e 00/14030-9).

Finalmente, gostaríamos de agradecer, sem exceção, a todos os proprietários das terras onde localizam-se os trechos de riachos visitados pelo total, irrestrito, e até mesmo muitas vezes caloroso, apoio recebido, sem o qual este trabalho não teria sido possível.

\section{Referências bibliográficas}

AGOSTINHO, A.A. \& JÚLIO Jr., H.F. 1999. Peixes da bacia do Alto rio Paraná. In Lowe-McConnell, R. H. Estudos ecológicos de comunidades de peixes tropicais (A.E.A.M. Vazzoler, A.A. Agostinho \& P.T. Cunningham, tradutores.). EDUSP, São Paulo, p. 374-400.

AGOSTINHO, A.A., VAZZOLER, A.E.A.M. \& THOMAZ, S.M. 1995. The high river Paraná basin: limnological and ichthyological aspects. In Limonology in Brazil (T.M. Tundisi, G. Tundisi \& C.E.M. Bicudo, eds.). ABC/SBL, Rio de Janeiro, p. 59-103.

ALVARENGA, S.M., SILVA, J.E.B. \& NUNES, P.S. 1997. Unidades de Relevo. In Recursos Naturais e Meio Ambiente: Uma visão do Brasil. IBGE, Rio de Janeiro, $208 \mathrm{p}$.

ARANHA, J. M. R., TAKEUTI D. F. \& YOSHIMURA, T. M. 1998. Habitat use and food partitioning of the fishes in a coastal stream of Atlantic Forest, Brazil. Rev. Biol. Trop. 46: 951-959.

ARCIFA, M. S. \& MESCHIATTIA.J.1993. Distribution and feeding ecology of fishes in a Brazilian Reservoir: lake Monte Alegre. Interciência 18: 302-313.

BENINE, R.C. 2000. Taxonomia e relações filogenéticas de Gymnocorymbus Eigenmann, 1908 (Characiformes: Characidae). Dissertação de Mestrado, Universidade Estadual Paulista, Botucatu.

BRITTO, M.R. \& CASTRO, R.M.C. 2002. New Corydoradinae catfish (Silurformes: Callichthyidae) from the Upper Paraná and São Francisco: the sister group of Brochis and most of Corydoras species. Copeia 2002:1006-1015.

BROWER, J.E. \& ZAR, J.H. 1984. Field and laboratory methods for general ecology. Wm. C. Brown Publishers, Dubuque, $226 \mathrm{p}$.

BUCK, S. \& SAZIMA I. 1995. An assemblage of mailed catfishes (Loricariidae) in southeastern Brazil: distribution, activity and feeding. Ichthyol. Explor. Freshwaters 6:325-332.
CASATTI, L. 2002. Alimentação dos peixes em um riacho do Parque Estadual Morro do Diabo, bacia do Alto Rio Paraná, Sudeste do Brasil. Biota Neotropica 2:1-14 (www.biotaneotropica.org.br).

CASATTI, L. \& CASTRO, R.M.C. 1998. A fish community of the São Francisco River headwaters riffles, southeastern Brazil. Ichthyol. Explor. Freshwaters 9:229-242.

CASATTI, L., LANGEANI, F. \& CASTRO, R.M.C. 2001. Peixes de riacho do Parque Estadual Morro do Diabo, bacia do Alto Rio Paraná, SP. Biota Neotropica 1:1-15 (www.biotaneotropica.org.br).

CASATTI, L., MENDES, H.F. \& FERREIRA, K.M. 2003. Aquatic macrophytes as feeding site for small fishes in the Rosana Reservoir, Paranapanema River, southeastern Brazil. Braz. J. Biol. 63:213-222.

CASTRO, R.M.C. 1999. Evolução da ictiofauna de riachos sul-americanos: padrões gerais e possíveis processos causais. In Ecologia de Peixes de Riachos: Estado Atual e Perspectivas (E.P. Caramaschi, R. Mazzoni, C.R.S.F. Bizerril, P.R. Peres-Neto, eds.). Oecologia Brasiliensis, v. VI, Rio de Janeiro, p. 139-155.

CASTRO, R.M.C. \& CASATTI, L. 1997. The fish fauna from a small forest stream of the upper Paraná River Basin, southeastern Brazil. Ichthyol. Explor. Freshwaters 7:337352.

CASTRO, R.M.C. \& MENEZES, N.A. 1998. Estudo diagnóstico da diversidade de peixes do Estado de São Paulo. In Biodiversidade do Estado de São Paulo, Brasil: síntese do conhecimento ao final do século XX, vol. 6 Vertebrados (R.M.C. Castro, ed., C.A. Joly \& C.E.M. Bicudo, orgs.). WinnerGraph - FAPESP, São Paulo, p. 113.

CASTRO, R.M.C., CASATTI, L., SANTOS, H.F., FERREIRA, K.M., RIBEIRO, A.C., BENINE, R.C., DARDIS, G.Z.P., MELO, A.L.A., STOPIGLIA, ABREU, T.X., BOCKMANN, F.A., CARVALHO, M., GIBRAN, F.Z. \& LIMA, F.C.T. 2003a. Estrutura e composição da ictiofauna de riachos do Rio Paranapanema, sudeste e sul do Brasil. Biota Neotropica 3:1-31 (www.biotaneotropica.org.br).

CASTRO, R.M.C., RIBEIRO, A.C., BENINE, R.C. \& MELO, A. L. A. 2003b. Lophiobrycon weitzmani, a new genus and species of glandulocaudinae fish (Characiformes: Characidae) from the rio Grande drainage, upper rio Paraná system, southeastern Brazil. Neotropical Ichthyology 1:11-19.

CEMIG \& CETEC. 2000. Guia ilustrado de peixes da bacia do Rio Grande. Companhia Energética de Minas Gerais e Fundação Centro Tecnológico de Minas Gerais, Belo Horizonte, $141 \mathrm{p}$. 
COLWELL, R.K. 1997. EstimateS 5. Statistical estimation of species richness and shared species from samples. Version 5.0.1 (viceroy.eeb.uconn.edu/estimates, 08.ix.2001), University of Connecticut.

COSTA, W.J.E.M. 1987. Feeding habits of a fish community in a tropical coastal stream, rio Mato Grosso, Brasil. Stud. Neotr. Fauna Envir. 22: 145-153.

ESTEVES, K.E. \& GALETTI JR, P. M. 1995. Food partitioning among some characids of a small Brazilian floodplain lake from the Paraná River basin. Envir. Biol. Fish. 42: 375-389.

ESTEVES, K.E. 1996. Feeding ecology of three Astyanax species (Characidae, Tetragonopterinae) from a floodplain lake of Mogi-Guaçu River, Paraná River Basin, Brazil. Envir. Biol. Fish. 46: 83-101.

FERNANDES, L.A. \& COIMBRA, A.M. 2000. Revisão estratigráfica da parte ocidental da bacia Baurú (Neocretáceo). Revista Brasileira de Geociências 30:717728.

FERREIRA, K.M. 2002. Aspectos da biologia e ecomorfologia dos peixes de um riacho da bacia do rio Mogi-Guaçu, SP. Dissertação de Mestrado, Universidade de São Paulo, Ribeirão Preto, 139 p.

GARUTTI, V. 1988. Distribuição longitudinal da ictiofauna de um córrego na região noroeste do Estado de São Paulo, Bacia do Rio Paraná. Rev. Bras. Biol. 48:747-759.

GARUTTI, V. 1989. Contribuição ao conhecimento reprodutivo de Astyanax bimaculatus (Ostariophysi, Characidae), em cursos de água da bacia do Rio Paraná. Rev. Brasil. Biol. 49:489-495.

GARUTTI, V. \& BRITSKI, H.A. 2000. Descrição de uma espécie nova de Astyanax (Teleostei: Characidae) da bacia do alto rio Paraná e considerações sobre as demais espécies do gênero na bacia. Comun. Mus. Ciên. PUCRS, Sér. Zool, Porto Alegre 13:65-88.

GÉRY, J. 1969. The fresh-water fishes of South America. In Biogeography and ecology in South America, vol. 2 (E. J. Fittkau et al., eds.). Junk, The Hague, p. 828-848.

GODOY, M.P. 1975. Peixes do Brasil: subordem Characoidei; bacia do Rio Mogi Guassu. Ed. Franciscana, Piracicaba, v. 1, p. 1-216.

HUECK, K. \& SEIBERT, P. 1981. Vegetationskarte von Südamerika. Band IIa. Fischer, Sttutgart, 90 p.

KULLANDER, S.O. 2003. Family Cichlidae (Cichlids). In Check list of the freshwater fishes of South and Central America (R.E. Reis, S.O. Kullander \& C.J. Ferraris Jr., orgs.). EDIPUCRS, Porto Alegre, p. 605-654.

LEE, S.M. \& CHAO, A. 1994. Estimating population size via sample coverage for closed capture-recapture models. Biometrics 50:88-97.
LOWE-McCONNELL, R.H. 1987. Ecological studies in tropical fish communities. Cambridge Univ. Press, Cambridge, $382 \mathrm{p}$.

LOWE-McCONNELL, R.H. 1999. Estudos ecológicos de comunidades de peixes tropicais. Editora da Universidade de São Paulo, São Paulo, Brasil, 534 p.

LUDWIG, J.A. \& REYNOLDS, J.F. 1988. Statistical ecology: a primer on methods and computing. John Wiley \& Sons, New York, $337 \mathrm{p}$.

LUIZ, E.A., AGOSTINHO, A.A., GOMES, L.C. \& HAHN, N.S. 1998. Ecologia trófica de peixes em dois riachos da bacia do Rio Paraná. Rev. Brasil. Biol. 58:273-285.

NIMER, E. 1989. Climatologia do Brasil. Secretaria de Planejamento e Coordenação da Presidência da República e IBGE, Rio de Janeiro, Brasil, 421 p.

OBARA, E. \& MENDES, L. F. 1990. Aspectos da biologia dos peixes de um trecho da cabeceira do ribeirão Tamanduá, bacia do Rio Pardo, SP. Monografia de Conclusão de Curso, Departamento de Biologia, Universidade de São Paulo, Ribeirão Preto, 68 p.

OYAKAWA, O.T. 2003. Family Eryhrinidae (Trahiras). In Check list of the freshwater fishes of South and Central America (R.E. Reis, S.O. Kullander \& C.J. Ferraris Jr., eds.). EDIPUCRS, Porto Alegre, p. 238-240.

PAVANELLI, C.S. \& CARAMASCHI, E.P. 1997. Composition of the ichthyofauna of two small tributaries of the Paraná river, Porto Rico, Paraná State, Brazil. Ichthyol. Explor. Freshwaters 8:23-31.

PENCZAK, T., AGOSTINHO, A.A. \& OKADA, E.K. 1994. Fish diversity and community structure in two small tributaries of the Paraná River, Paraná State, Brazil. Hydrobiol. 294:243-251.

PESQUISA FAPESP. 2003. O verde em São Paulo. Fundação de Amparo à Pesquisa do Estado de São Paulo, São Paulo, n. 91 (encarte especial).

PETRI, S. \& FÚLFARO, V.J. 1983. Geologia do Brasil. EDUSP, São Paulo, 631 p.

POWER, M. 1984 a. Grazing responses of tropical freshwater fishes to different scales of variation in their food. In Evolutionary Ecology of Neotropical Freshwater Fishes (T.M. Zaret, ed.). Dr. W. Junk Publ., Netherlands, p. 2537.

POWER, M. 1984 b. Depth distributions of armored catfish: predator-induced resource avoidance? Ecology, 65: 523528.

POWER, M. 1990. Resource enhancement by indirect effects of grazers: armored catfish, algae and sediment. Ecology, 71: 897-904. 
REIS, R.E., KULLANDER, S.O. \& FERRARIS, C.(Eds.). 2003. Check List of the Freshwater Fishes of South and Central America (CLOFFSCA), EDIPUCRS, Porto Alegre., $729 \mathrm{p}$.

SABINO, J. 2000. Estudo comparativo em comunidades de peixes de riachos da Amazônia Central e Mata Atlântica: distribuição espacial, padrões de atividade e comportamento alimentar. Tese de Doutorado, Universidade Estadual de Campinas, Campinas, 134 p.

SABINO, J. \& ZUANON, J.1998. A stream fish assemblage in Central Amazonia: distribution, activity patterns and feeding behavior. Ichthyol. Explor. Freshwaters, 8: 201210.

SCHROEDER-ARAÚJO, L.T. 1980. Alimentação dos peixes da represa de Ponte Nova, Alto Tietê, São Paulo. Tese de Doutorado, Universidade de São Paulo, São Paulo, $88 \mathrm{p}$.

SABINO, J. \& CASTRO, R.M.C. 1990. Alimentação, período de atividade e distribuição espacial dos peixes de um riacho da floresta Atlântica (sudeste do Brasil). Rev. Brasil. Biol. 50:23-36.

SAZIMA, I. 1986. Similarities in feeding behaviour between some marine and freshwater fishes in two tropical communities. J. Fish. Biol. 29:53-65.

SILVA, A.M. \& MARTINELLLI, L.A. 2002. Cobertura e uso do solo e ecologia da paisagem para sete bacias hidrográficas do Estado de São Paulo. Resumos III Simpósio do Programa BIOTA/FAPESP, São Carlos.

SILVA, C.P.D. 1993. Alimentação e distribuição espacial de algumas espécies de peixes do igarapé do Candirú, Amazonas, Brasil. Acta Amazonica, 23 : 271-285.

STRAHLER, A.N. 1957. Quantitative analysis of watershed geomorphology. Trans. Amer. Geoph. Union 38:913-920.

SOARES, M. G. M. 1979. Aspectos Ecológicos (alimentação e reprodução) dos peixes do igarapé do Porto, Aripuanã, MT.Acta Amazônica, 9: 325-352.

TEIXEIRA, R. L. 1989. Aspectos da ecologia de alguns peixes do arroio Bom Jardim, Triunfo, RS. Rev. Brasil. Biol., 49: 183-192.

UIEDA, V.S. 1984. Ocorrência e distribuição dos peixes em um riacho de água doce. Rev. Brasil. Biol. 2:203-213.

UIEDA, V.S., BUZZATO, P. \& KIKUCHI, R.M. 1997. Partilha de recursos alimentares em peixes em um riacho de serra no Sudeste do Brasil. An. Acad. Bras. Ci. 69:243-252.

USHIROHIRA, J. 1970. Crescimento e alimentação de três subespécies de peixes do gênero Astyanax Baird \& Girard 1854 (Pisces, Characidae) do rio Mogi-Guaçu, SP. Monografia de Conclusão de Curso, Departamento de Biologia, Universidade de São Paulo, Ribeirão Preto, 34 p.
WEITZMAN, S.H. \& PALMER, L. 1997. The common serpa tetra of aquarists: identified as Hyphessobrycon eques (Steindachner, 1882). Trop. Fish. Hob. 45:140-150.

WISCHNATH, L. 1993. Atlas of livebearers of the world. T.H.F. Publications, Neptune City, 336 p.

ZIESLER, R. \& ARDIZZONE, G.D. 1979. The inland waters of Latin America. Copescal Technical Paper No. 1. Food and Agriculture Organization of the United Nations (FAO), Roma, 171 p.

Título: Estrutura e composição da ictiofauna de riachos da bacia do Rio Grande no Estado de São Paulo, sudeste do Brasil

Autores: Ricardo M. C. Castro; Lilian Casatti; Hertz F. Santos; Alex L. A. Melo; Luiz S. F. Martins; Katiane M. Ferreira; Fernando Z. Gibran; Ricardo C. Benine; Murilo Carvalho; Alexandre C. Ribeiro; Tatiana X. Abreu; Flávio A. Bockmann; Gabriela Z. Pelição; Renata Stopiglia \& Francisco Langeani

Biota Neotropica, Vol. 4( number 1): 2004

http://www.biotaneotropica.org.br/v4n 1/pt/ abstract?article+BN01704012004

Recebido em: 5/12/2003 Publicado em: 30/04/2004 ISSN 1676-0603 